\title{
ChARACTERIZATION AND GRADING OF NATURAL-COLOR YELLOW DIAMONDS
}

\author{
John M. King, James E. Shigley, Thomas H. Gelb, Scott S. Guhin, Matthew Hall, and Wuyi Wang
}

To better understand the yellow diamonds currently in the marketplace, as well as identify possible changes in their trends seen over a five-year period, researchers at the GIA Gem Laboratory analyzed gemological data collected on more than 24,000 natural-color yellow diamonds examined in the calendar years 1998 and 2003. These data included color grade, type of cut, clarity grade, weight, ultraviolet fluorescence, and UV-visible and infrared spectra. Among natural-color colored diamonds, those with a yellow hue are some of the most abundant; even so, they are much less common than the colorless to light yellow diamonds associated with GIA's D-to-Z color grading scale. Since the yellow color is a continuation of the gradation of color associated with the D-to-Z scale, there can be misconceptions about the color grading, which involves different procedures from those used for D-to-Z grading. The grading and appearance aspects, as well as other characteristics of yellow diamonds, are discussed to clarify these differences. The authors have also identified five subgroups of type I yellow diamonds, which (with some overlap) are characterized by representative spectra and color appearances.

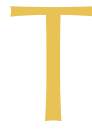

oday, yellow diamonds are among the most widely encountered of the "fancy color" diamonds (figure 1). From 1998 to the present, GIA has issued grading reports on more than 100,000 yellow diamonds, by far the most common of the fancy-color diamonds submitted to our laboratory. In 2003, for example, $58 \%$ of the diamonds submitted for GIA Colored Diamond Grading Reports or Colored Diamond Identification and Origin of Color Reports were in the yellow hue. Nevertheless, these represented only $2.4 \%$ of all diamonds submitted for various grading reports that year. The dichotomy between being common among colored diamonds yet relatively rare overall has created a mix of information and sometimes erroneous assumptions about yellow diamonds. In addition, although information about their "origin of color" or unusual characteristics (see below) has been documented over the years, little has been published about their color appearance and its relationship to color grading (one exception being Hofer, 1998).
This article presents data on more than 24,000 fancy-color yellow diamonds that were examined by the GIA Gem Laboratory during the years 1998 and 2003. While our main concern in this study was gathering information to characterize the gemological and spectroscopic properties of the entire population of samples, we were also interested in identifying any trends in size, color grade, or clarity grade among the yellow diamonds submitted to us that might be revealed over time. To that end, we selected a sample population from these two years separated by a five-year span.

Following a brief review of the literature on the geographic sources, cause of color, and other physical properties of fancy-color yellow diamonds, this article will focus on expanding the published information about these diamonds by documenting and

See end of article for About the Authors and Acknowledgments. GeMs \& GemOlogy, Vol. 41, No. 2, pp. 88-115.

(C) 2005 Gemological Institute of America 


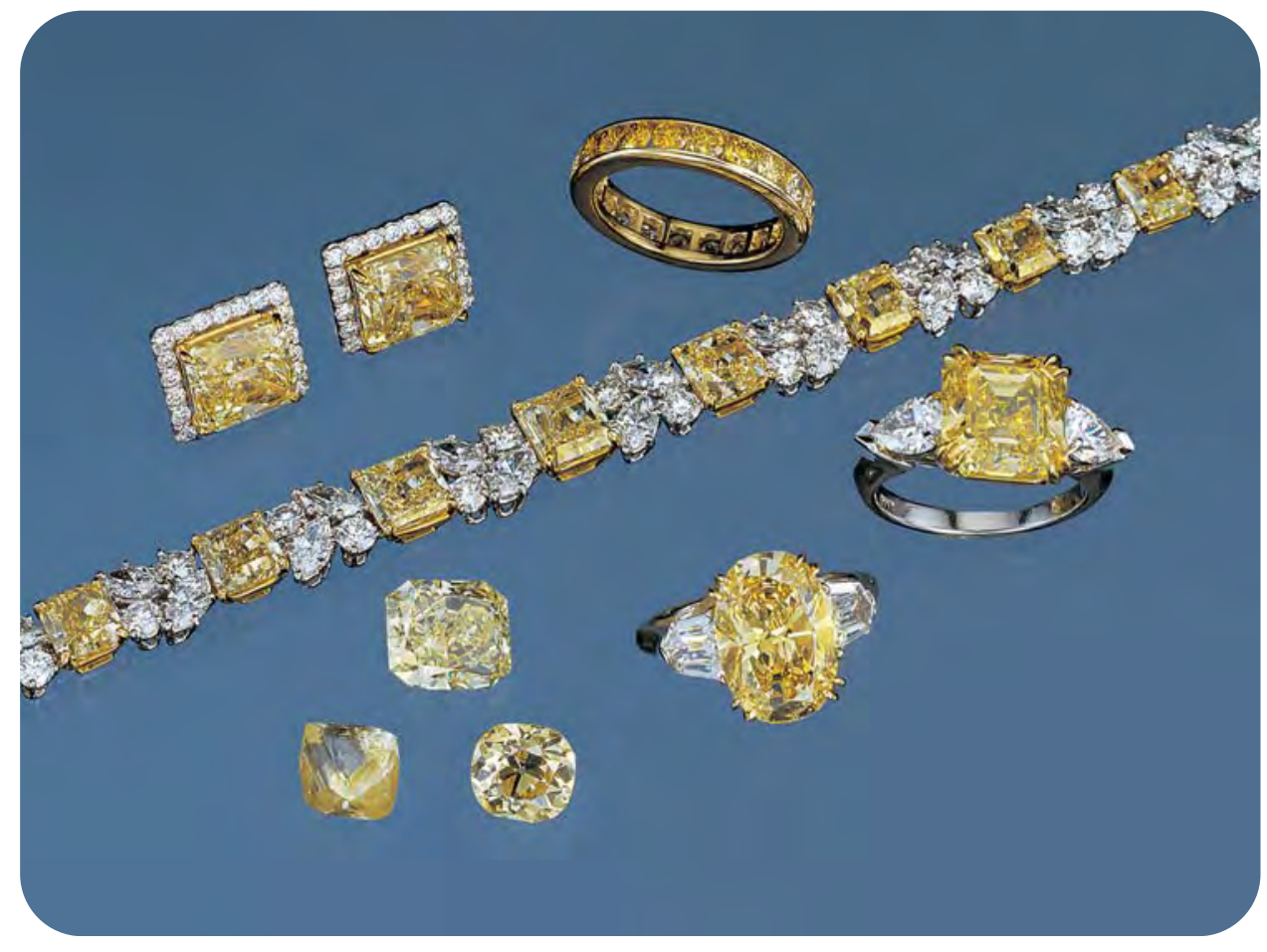

Figure 1. While abundant compared to other colored diamonds, fancy-color yellow diamonds represent a small portion of overall diamond production. Their beauty and the depths of color in which they occur offer a wide range of possibilities to the jeweler. The bracelet and the $4.13 \mathrm{ct}$ oval and 6.20 ct emerald cut in the rings are courtesy of Harry Winston Inc.; the 8.70 ct (total weight) StarBurst cuts in the earrings are courtesy of Jonathan Doppelt Inc.; the yellow gradation eternity band is courtesy of N. Smid; and the two unmounted diamonds and the crystal are courtesy of the Scarselli family. Photo by Harold $\uplus$ Erica Van Pelt.

reporting on their range of color, color grading, clarity grading, and other gemological properties, as well as their spectroscopic characteristics.

We will also look at a number of aspects of color observation and appearance (as they apply to these diamonds) that are known and commonly addressed by vision scientists but may not be recognized by the layperson or even the experienced diamond dealer or retailer. As with the previous GIA studies of blue and pink diamonds (King et al., 1998, 2002), this article describes and illustrates some of these aspects to aid in understanding how they apply to color grading yellow diamonds.

\section{BACKGROUND}

History and Geographic Origin. Yellow diamonds have long been recognized and prized among collectors (Mawe, 1813; Bauer, 1904; Copeland and Martin, 1974; Gleason, 1985). For example, in his description of several famous diamonds he encountered while in India, the French traveler and gem dealer Jean-Baptiste Tavernier (1676) mentioned seeing a $137.27 \mathrm{ct}$ yellow diamond that he referred to variously as the "Florentine," the "Austrian Yellow," and the "Grand Duke of Tuscany." As with other colors, yellow diamonds have come to the public's attention through the interest generated by a number of special stones, such as the historical 128.54 ct Tiffany (figure 2; see Balfour, 2000) and 101.29 ct Allnat (see King and Shigley, 2003) diamonds, or the extraordinary $407.48 \mathrm{ct}$ Incomparable (illustrated in King et al., 1994, p. 227). Indeed, the first reportedly authenticated diamond found in Africa, which was cut into the 10.73 ct Eureka, is a distinct yellow (Balfour, 2000; shown in Janse, 1995, p. 231). Its discovery in late 1866/early 1867 helped start the ensuing African diamond mining rush.

Although there were occasional finds over the centuries in India, Brazil (Cassedanne, 1989), and perhaps elsewhere, the first major discovery of quantities of what today would be considered fancycolor yellow diamonds occurred at several locations in South Africa in the late 1860s (Janse, 1995; figure 3 ). The early preponderance of light yellow diamonds from the Cape Province in South Africa led to their description in the jewelry trade as "cape stones," a usage that continues today (see, e.g., GIA Diamond Dictionary, 1993). While these light yellow diamonds are not now considered colored diamonds (rather, they fall toward the lower end of GIA's D-to-Z color scale), their noticeable color distinguished them from those of other deposits that yielded near-colorless or brown diamonds. Also found, however, were numerous diamonds that ultimately would be considered yellow. The earliest recorded find along the banks of the Orange River was, as noted above, a 21.25 ct (old carat weight) yellow crystal that was subsequently cut into the 


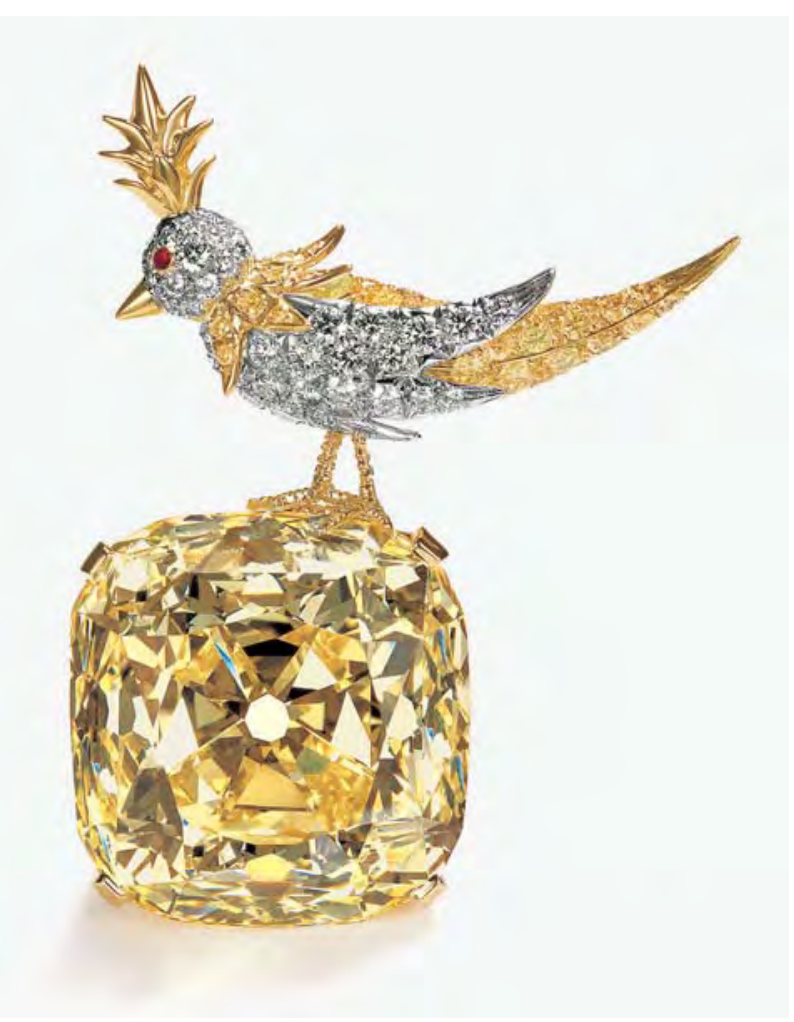

Figure 2. The Tiffany yellow diamond is one of the best-known diamonds in the world. The $128.54 \mathrm{ct}$ diamond has been in the Tiffany collection since 1879, and today it is displayed in its own case (as part of Jean Schlumberger's jewel, "Bird on a Rock") at Tiffany et Co. in New York City. It was graded by GIA in 1984. Photo courtesy of Tiffany « Co.

Eureka (Janse, 1995). In 1878 , a 287.42 ct piece of rough recovered from a claim on the Kimberley mine was later fashioned into the Tiffany diamond (again, see figure 2). In 1964, the Dutoitspan mine yielded a spectacular $253.70 \mathrm{ct}$ transparent yellow octahedral crystal known as the Oppenheimer diamond, which now resides in the Smithsonian Institution.

Today, yellow diamonds are found in the productions of mining operations throughout the world (Field, 1992, p. 353). The occurrence of fancycolor yellow diamonds is so widespread that no particular deposit stands out as an important source (though many of the larger pieces of yellow rough continue to originate from South Africa). Some data correlating diamond color and size has been published for certain deposits (in particular, the kimberlites in South Africa; see, e.g., Harris et al., 1979|, but the literature contains no such information on yellow diamond abundances for other occurrences.
Noted Auction Sales and Other Publicity. As with other colored diamonds, yellow diamonds can command high prices and generate much public attention. At its 1988 auction, the Fancy brownish yellow* Internally Flawless Incomparable diamond reached a bid of $\$ 12$ million before it was withdrawn without having met its reserve (Balfour, 1997). An $18.49 \mathrm{ct}$ Fancy Intense" yellow known as the "Golden Drop" sold at auction for \$203,461 per carat in 1990 (Hofer, 1998), while a 13.83 ct Fancy Vivid yellow sold for $\$ 238,792$ per carat in 1997. In February 2005, a 10.02 ct Fancy Vivid yellow diamond sold for $\$ 772,848$ (more than $\$ 77,131$ per carat) at Sotheby's St. Moritz. Recently, a 101.28 ct Fancy Vivid yellow cushion modified brilliant known as the "Golden Star" was unveiled to the public in Palm Beach, Florida, by jeweler Laurence Graff, who reported that this diamond had been cut from a large crystal found at the Finsch mine in South Africa.

Past Studies. Differences noted in crystal form and physical and spectroscopic properties between (what were discovered to be) nitrogen-containing diamonds and those much rarer diamonds with virtually no nitrogen led early in the 20th century to the recognition by scientists of the type I and type II categories, respectively (Robertson et al., 1934; also see Anderson, 1963). At the atomic level in type I diamonds, nitrogen substitutes for carbon as either multiple atoms (aggregates) that occupy adjacent positions in the lattice (type Ia) or as single isolated atoms (type Ib).

There have been several recent reviews of the physical properties of diamond, including Field (1992), Davies (1994), and Wilks and Wilks (1994). A number of articles have discussed the visible and infrared spectra of yellow diamonds as they relate to the discrimination of natural-color diamonds from those that have been treated to change their color (Clark et al., 1956a,b; Crowningshield, 1957-8; Scarratt, 1979, 1982; Collins, 1978, 1982a,b, 2001; Woods and Collins, 1982, 1986; Woods, 1984; Collins et al., 1986; Mita, 1996; Fritsch, 1998; Haske, 2000; Kaminsky and Khachatryan, 2001; De Weerdt and Van Royen, 2001; Zaitsev, 2001). Additional articles have discussed the potential use of spectral measurements to quantitatively evaluate the color of faceted yellow diamonds (Vendrell-Saz et al., 1980; Sato and Sunagawa, 1982; Collins, 1984).

\footnotetext{
* Graded prior to modifications to GIA's colored diamond color grading system in 1995.
} 
Gemologists have also recognized that certain inclusions are characteristic of particular gemstones and, as such, help provide information on their geologic history and diamond type. For example, Crowningshield (1959) reported that needlelike inclusions, as well as oriented plate-like inclusions, are found on occasion in some yellow diamonds. Such inclusions were later associated with type Ib yellow diamonds (Crowningshield, 1994).

Color and Color Origin. In general, the presence of nitrogen atoms gives rise to two kinds of absorption in the blue region of the visible spectrum; the remainder of the spectrum is transmitted, leading to an observed yellow color. In type Ia diamond, aggregates of nitrogen atoms in the form of the N3 center cause absorption as a sharp line at $415 \mathrm{~nm}$. The N3 center is believed to consist of three nearest-neighbor substitutional nitrogen atoms all bonded around a common lattice site of a missing carbon atom (a vacancy). This absorption produces the lighter yellow coloration typical of "cape" diamonds.

The same N3 center is also responsible for blue long-wave ultraviolet fluorescence when seen in type Ia diamonds (Nayar, 1941; Mani, 1944; Dyer and Matthews, 1957). Based largely on observations with the prism spectroscope, Anderson (1943a,b, 1962) noted the general correlation between the intensity of the $415 \mathrm{~nm}$ absorption band and the strength of the diamond's yellow color (also see Anderson and Payne, 1956). Occasionally, the N3 center is accompanied by additional broader but weaker lines at 452,465 , and $478 \mathrm{~nm}$ (the N2 center; see Clark et al., 1956a; Davies et al., 1978; Davies, 1981), which also contribute to the yellow color. These lines are superimposed over a region of absorption that increases gradually toward the blue end of the spectrum.

Collins (1980) gave nitrogen concentration values of up to $3000 \mathrm{ppm}$ for type Ia diamonds. Two additional nitrogen aggregates-designated $A$ (a pair of nearest-neighbor nitrogen atoms) and $B$ (four $\mathrm{N}$ atoms surrounding a vacancy)—are usually present in type Ia diamonds, but neither gives rise to absorption in the visible region (thus, they do not produce any coloration, but they do produce characteristic absorption features in the infrared spectrum).

In the much-less-common type Ib diamond, single-substitutional nitrogen atoms cause a broad region of absorption that increases below about $560 \mathrm{~nm}$ (but no sharp $415 \mathrm{~nm}$ absorption band), which in turn produces a more saturated yellow color. In some cases, type $\mathrm{Ib}$ diamonds exhibit a very weak to weak yellow or orange short-wave UV fluorescence (see Dyer et al., 1965; Fritsch, 1998, pp. 26-30 and 36-37; Hofer, 1998, pp. 354-359). Such diamonds have often been described as having a "canary" color (Wade, 1920; Anderson, 1943a; Liddicoat, 1976). In contrast to type Ia yellow diamonds, those that are type Ib contain much smaller amounts of nitrogen, normally well under 100 ppm (Collins, 1980; Field, 1992).

These subcategories of type I diamonds can be distinguished on the basis of characteristic features in their visible and infrared absorption spectra. It should be mentioned that these subcategories are not mutually exclusive, since at the atomic level the diamond lattice can contain different ratios of aggregated and isolated nitrogen atoms from one diamond to the next. In addition, infrared spectral features associated with both isolated and aggregated forms of nitrogen can be recorded from different portions within the same diamond. For example,

Figure 3. The late 1860s saw the first major discovery of diamonds in South Africa, and with that came an influx of yellow rough into the market. The Kimberley and Dutoitspan mines, between the Orange and Vaal Rivers, were some of the significant early (and continuous) sources of production. In 1964, the latter mine yielded the spectacular 253.70 ct yellow octahedral crystal known as the Oppenheimer diamond. Modified from Janse (1995).

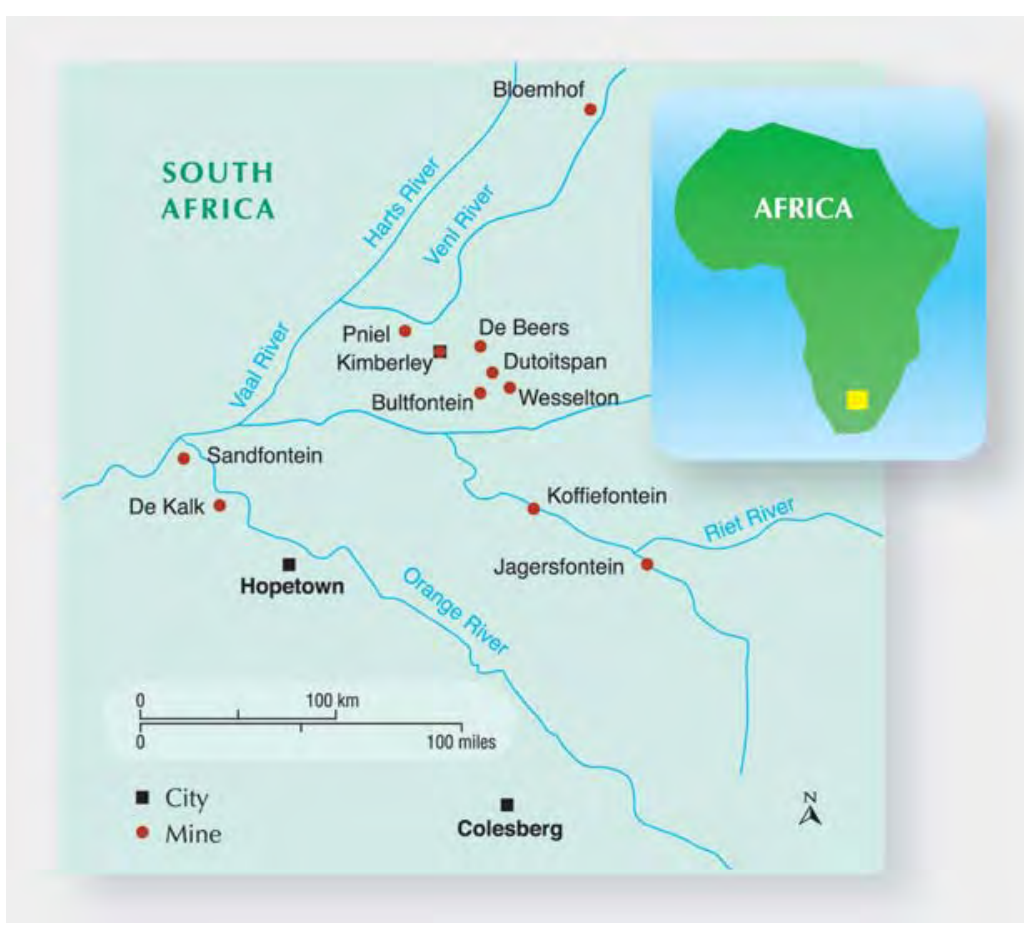


Collins (1980) suggested that many type Ib diamonds also contain A-aggregates (type IaA) of nitrogen. For additional information on diamond types and optical centers, see Davies (1972); Davies and Summersgill (1973); Collins (1982a,b, 2001); Bursill and Glaisher (1985); Fritsch and Scarratt (1992, pp. 38-39); Briddon and Jones (1993); Wilks and Wilks (1994); and De Weerdt and Van Royen (2001).

GIA Color Descriptions for "Yellow" Diamonds. A hue has different color appearances depending on its tone and saturation (King et al., 1994, 2002). The color description that GIA gives diamonds on grading reports is based on the hue, and on the tone and saturation of that hue. For example, when a yellow hue becomes darker in tone and weaker in saturation, it appears increasingly brown, and this is reflected in the color description (i.e., brownish yellow). In certain darker/weaker areas of the yellow hue range, the color appears to have both brown and green components (as compared to similar tones and saturations of adjacent hues), which results in descriptions such as brownish greenish yellow and brown-greenish yellow. Figure 4 illustrates these appearance relationships within and surrounding "yellow" on the hue circle. (For a more detailed discussion of the GIA color description system for colored diamonds, please see King et al., 1994.)

\section{MATERIALS AND METHODS}

Samples. The 24,668 diamonds reported on in this article were examined in $1998(7,213)$ and 2003 $(17,455)$ at our laboratories in New York and Carlsbad. The color of each was identified as being of natural origin (using standard and, where appropriate, advanced gemological testing) and was described on the grading report as being yellow, brownish yellow, brownish greenish yellow, or brown-greenish yellow (again, see figure 4). The diamonds ranged in weight from 0.30 to $219.35 \mathrm{ct}$.

For the purposes of this study, we did not include diamonds in the narrower greenish yellow, green-yellow, orangy yellow, or orange-yellow hues. Not only did these samples represent less than 13\% of the diamonds given "predominantly yellow" hues for the two years in which we retrieved data for this study-with no single hue representing more than 4\%-but they are also approached differently in their trading and valuation (K. Ayvazian, pers. comm., 2004).

Because of time constraints or the type of labo- ratory service requested by the client (e.g., a less comprehensive "identification and origin" report), the database does not include the same gemological observations for all the diamonds. For these reasons, we have indicated in the Results if the data being discussed originate from some smaller subset of these 24,668 diamonds.

Grading and Testing Methods. We used the GIA Gem Laboratory standard methodology for color grading colored diamonds to describe all of the study samples (see King et al., 1994). Screened and trained laboratory staff evaluated each of the diamonds using a standardized D65 "daylight-equivalent" lighting environment (as provided by the Macbeth Judge II illumination box). Typically, from three to six staff members independently compared the overall face-up characteristic color of each diamond to GIA colored diamond color references in order to determine the appropriate color description and location in GIA's color space.

Equipment used for the gemological examination included a standard gemological microscope, a GIA Gem Instruments ultraviolet unit with longwave $(365 \mathrm{~nm})$ and short-wave $(254 \mathrm{~nm})$ lamps, and a desk-model prism spectroscope.

Absorption spectra in the ultraviolet to visible (UV-Vis) range were recorded with a ThermoSpectronic Unicam UV500 spectrophotometer over the range $250-850 \mathrm{~nm}$ with a sampling interval of $0.1 \mathrm{~nm}$. The samples were mounted in a cryogenic cell and cooled using liquid nitrogen $\left(-196^{\circ} \mathrm{C}\right)$. Infrared absorption spectra were recorded in the mid-infrared (6000-400 cm-1 $1.0 \mathrm{~cm}^{-1}$ resolution) range at room temperature with a Thermo-Nicolet Nexus 670 Fourier-transform infrared (FTIR) spectrometer, equipped with a $\mathrm{KBr}$ beam splitter. A $6 \mathrm{x}$ beam condenser focused the incident beam on the sample, and a total of 1,024 scans (per spectrum) were collected to improve the signal-to-noise ratio. Diamond type was determined by infrared and visible spectroscopy. We selected a subset of 10,399 samples in order to study spectral differences within the two categories (Ia and $\mathrm{Ib}$ ) of type I yellow diamonds, and to see if there were any relationships between spectra and color appearance or observations with the microscope.

Absorption coefficients for all spectra were calculated assuming a straight light path through the faceted gemstone. Using absorption coefficients, we were able to calculate approximate nitrogen concentrations (Field, 1992). 


\section{YELLOW}

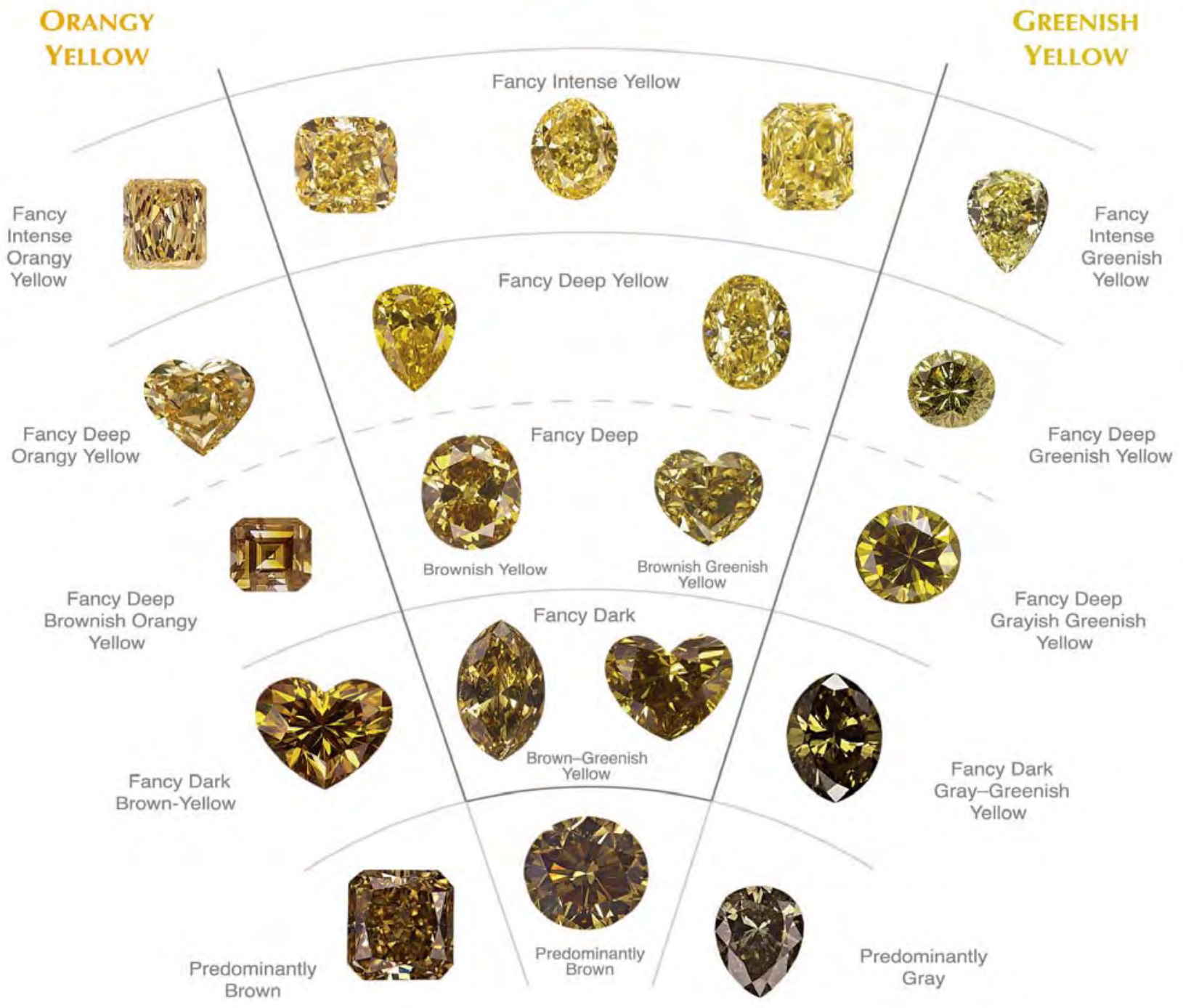

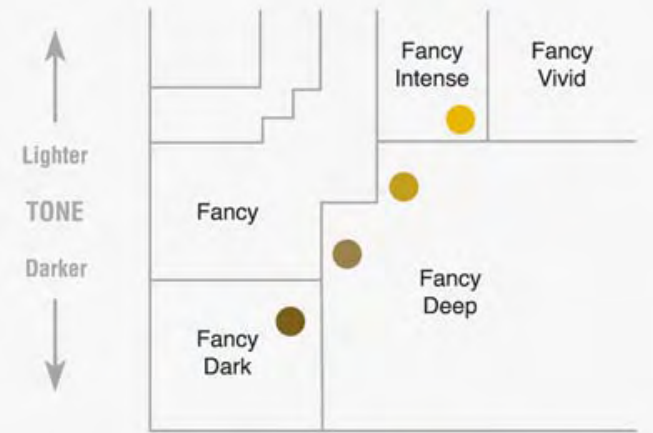

$\longleftarrow$ Weaker SATURATION Stronger $\longrightarrow$
Figure 4. The diamonds within the bold lines of this chart illustrate some of the color appearances seen among the samples in the study and the terms associated with them, which are based on hue, tone, and saturation. As shown here, diamonds in the yellow hue range often appear to have brown and green components as they become weaker and/or darker. For the purposes of this illustration, the transition in color seen from the outer ring (at the top) to the inner ring (at the bottom) is of weakening saturation and increasing darkness (as illustrated on the tone/saturation chart to the left). Examples from the adjacent hues of orangy yellow and greenish yellow are included here for comparison. Note that brown-yellow (and, if the full range was shown, yellow-brown and yellowish brown) is in the orangy yellow hue range, not the yellow range. 


\section{DATA ANALYSIS AND RESULTS}

Weight. A significant portion of our samples$30 \%$-weighed 3 ct or more, while $17 \%$ weighed 5 ct or more and $5 \%$ weighed more than $10 \mathrm{ct}$. Of the latter, 23 were larger than $50 \mathrm{ct}$, and three were larger than $100 \mathrm{ct}$. In general, there are slight (statistically insignificant) differences in these percentages for 1998 and 2003 (figure 5).

Cut. Yellow diamonds in the modern marketplace are most often fashioned as fancy shapes. This trend was apparent in our data, where $94 \%$ of the yellow diamonds examined were shapes other than round brilliants. Variations on the radiant cut are included in the "square" and "rectangular" categories that together represent $52 \%$ of all the diamonds studied (figure 6).

Color Appearance. Figure 7 illustrates the range of tones and saturations in which these yellow diamonds occur. As these charts illustrate, the colors of yellow diamonds transition smoothly throughout the ranges of hue, tone, and saturation (i.e., the changes in appearance are gradual without abrupt differences between them). The lighter, most-saturated colors are located toward the upper right corner of the charts (Fancy Intense, Fancy Vivid), while the darker, less-saturated colors lie toward the opposite corner (Fancy Dark). It is important to note that this distribution of color appearances differs from those of pink and blue diamonds (see King et al., 1998, 2002), where the stronger colors are darker in tone (i.e., toward the lower right corner of the chart). Five percent of the samples exhibited a brownish yellow, brownish greenish yellow, or brown-greenish yellow color appearance.

GIA Fancy Color Grades. The study samples covered all the GIA "fancy" grades associated with yellow diamonds (i.e., Fancy Light, Fancy, Fancy Intense, Fancy Dark, Fancy Deep, and Fancy Vivid). Unlike other colored diamonds (except brown), yellow diamonds with grades of Faint, Very Light, and Light are not considered to be fancy-colored diamonds, but are part of GIA's D-to-Z color grading scale.

The pie charts in figure 8 show how the yellow diamonds in our study fell into the fancy grade categories for 1998 and 2003. Colored diamond grading activity at GIA more than doubled from 1998 to 2003 , but, as seen in figure 8 , the general colorgrade distribution remained consistent during these two years.

\section{DISTRIBUTION BY WEIGHT}
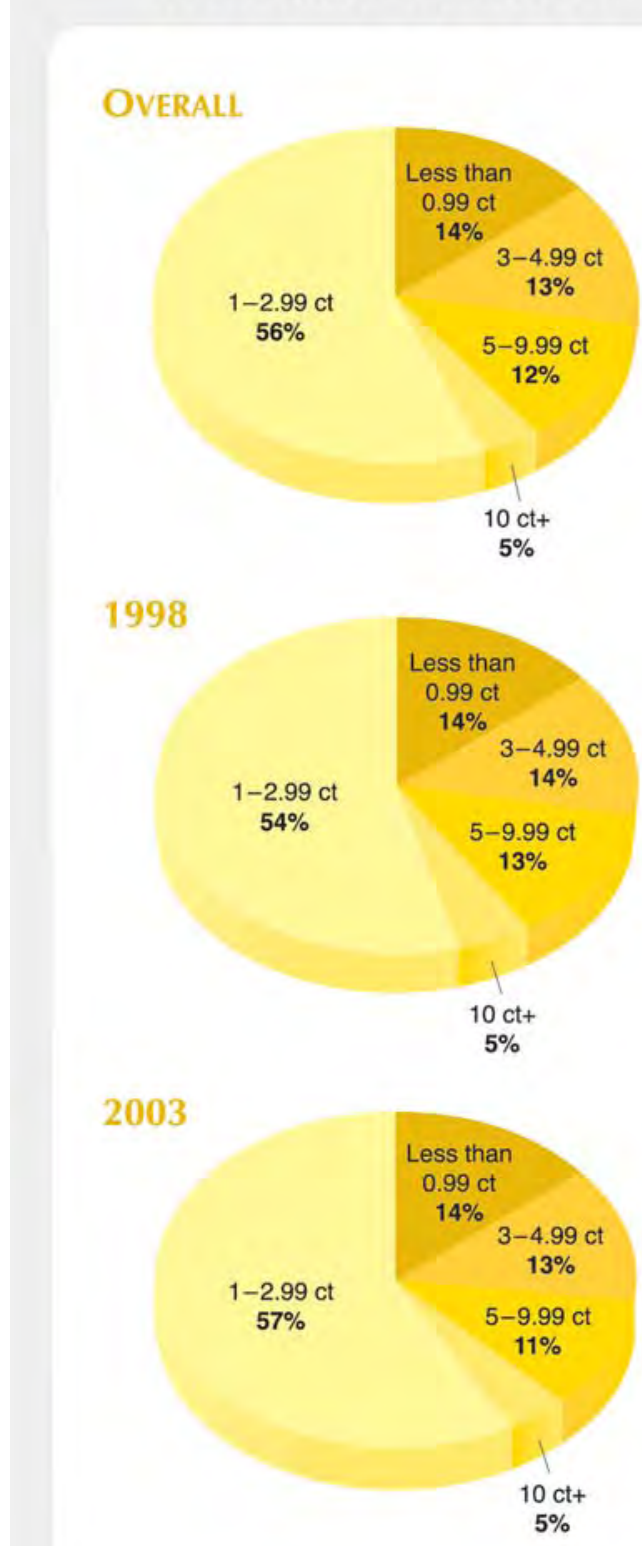

Figure 5. These three pie charts illustrate the distribution of the 24,668 diamonds in the study in several weight categories. The bottom two charts show that there was very little difference seen in the weight categories between 1998 and 2003.

Hue. As noted above, the diamonds in this study transition smoothly throughout the yellow hue range. This is consistent with GIA's observations of yellow diamonds over the past 50 years. At the extremes, two subtly different color appearances are 
observed ("cooler" toward the greenish yellow boundary and "warmer" toward orangy yellow) that are still described as yellow with no modifying terms (figure 9). In the more saturated grades of Fancy Intense and Fancy Vivid, the diamond community sometimes refers to these two appearances as "lemony" and "golden," respectively (N. Livnat, pers. comm., 2004).

Tone and Saturation. Yellow diamonds occur in broad ranges of tone and saturation. They reach their strongest saturation at relatively light tones (again, see figure 7), with saturation strengths as high as we have encountered for any other diamond color.

Microscopic Examination. Clarity Grades. Of the 17,152 diamonds examined for clarity, 30\% were VVS or Flawless/Internally Flawless (FL/IF), 50\% were Very Slightly Included (VS), and 20\% were Slightly Included (SI) or Included (I). Some variations were noted between samples graded in 1998 versus

Figure 6. This pie chart illustrates the percentage breakdown for the various shapes in which the yellow diamonds in our study were fashioned. Each shape category may include different cutting styles (such as step, modified brilliant, and brilliant cuts). Included in the miscellaneous category are shapes such as marquise, triangle, shield, kite, and briolette. The "cut-cornered or round-cornered rectangular/square" sections include variations on the radiant cut, which helped revolutionize the availability of fancy-color yellow diamonds in the marketplace.

\section{DISTRIBUTION BY SHAPE}

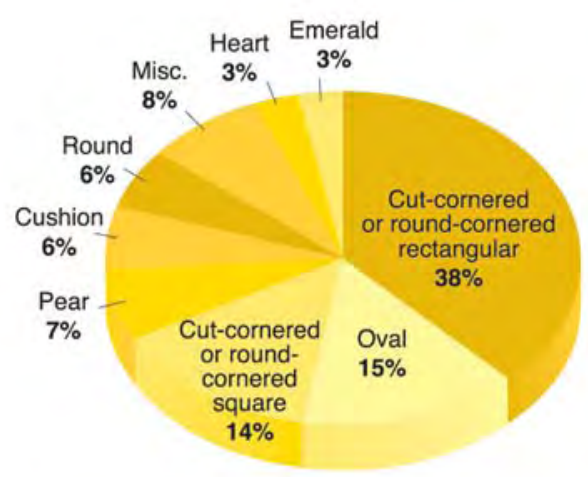

2003 (figure 10). For example, there was a decrease in the percentage of FL/IF (from 9\% to 5\%) and an increase in those graded SI (from 14\% to 19\%).

We were interested to see if there might be a correlation between depth of color and the clarity of the yellow diamonds in our study, so we reviewed the overall distribution of clarity grades for those diamonds graded Fancy Vivid versus those graded Fancy Light (as these two grades would represent the extremes in strength of color). In general, the distribution was similar (figure 11), although a higher percentage of Fancy Vivid diamonds received grades of Flawless or Internally Flawless (12\% versus $4 \%$ for the Fancy Light group); conversely, a higher percentage of Fancy Light diamonds received VS grades $155 \%$ versus $45 \%$ for the Fancy Vivid group).

Inclusions. It is common to encounter small clouds or strings of pinpoint-like solid inclusions in yellow diamonds (figure 12; see also Crowningshield, 1994). Occasionally dark crystals are seen as well (figure 13). We also noted the presence of small pinpoint or cloud-like inclusions toward the center of a number of the large (over $30 \mathrm{ct}$ ) diamonds in our study.

Graphite was the most common mineral inclusion observed, typically occurring in fractures of various sizes, displaying a flat shape. We occasionally observed euhedral crystals of both peridotitic and eclogitic minerals. Olivine (colorless), pyrope garnet (purple), and diopside (green) were observed as inclusions from the peridotitic group, which in general is more abundant in natural diamonds than the eclogitic group. From the eclogitic group, we usually found almandine-rich garnet (orange; figure 14), omphacite (grayish blue), and rutile (dark reddish orange). These inclusions were generally smaller than $100 \mu \mathrm{m}$, but they ranged up to several hundreds of micrometers in longest dimension. In rare cases, these inclusions displayed octahedral morphology. Over $80 \%$ of all natural diamonds are peridotitic (Meyer, 1987). However, in the majority of the yellow diamonds, it seems that macro inclusions of eclogitic group minerals were as common as those of peridotitic groups. Euhedral macro inclusions rarely occur in diamonds dominated by isolated nitrogen, and this was also the case for most of the type Ib diamonds examined in this study. What we did observe in a few of these type Ib samples, however, were small, needle-like fractures surrounding solid pinpoint inclusions. 


\section{Gia Yellow Diamond Color Chart}

\section{"WARMER" YelloW}

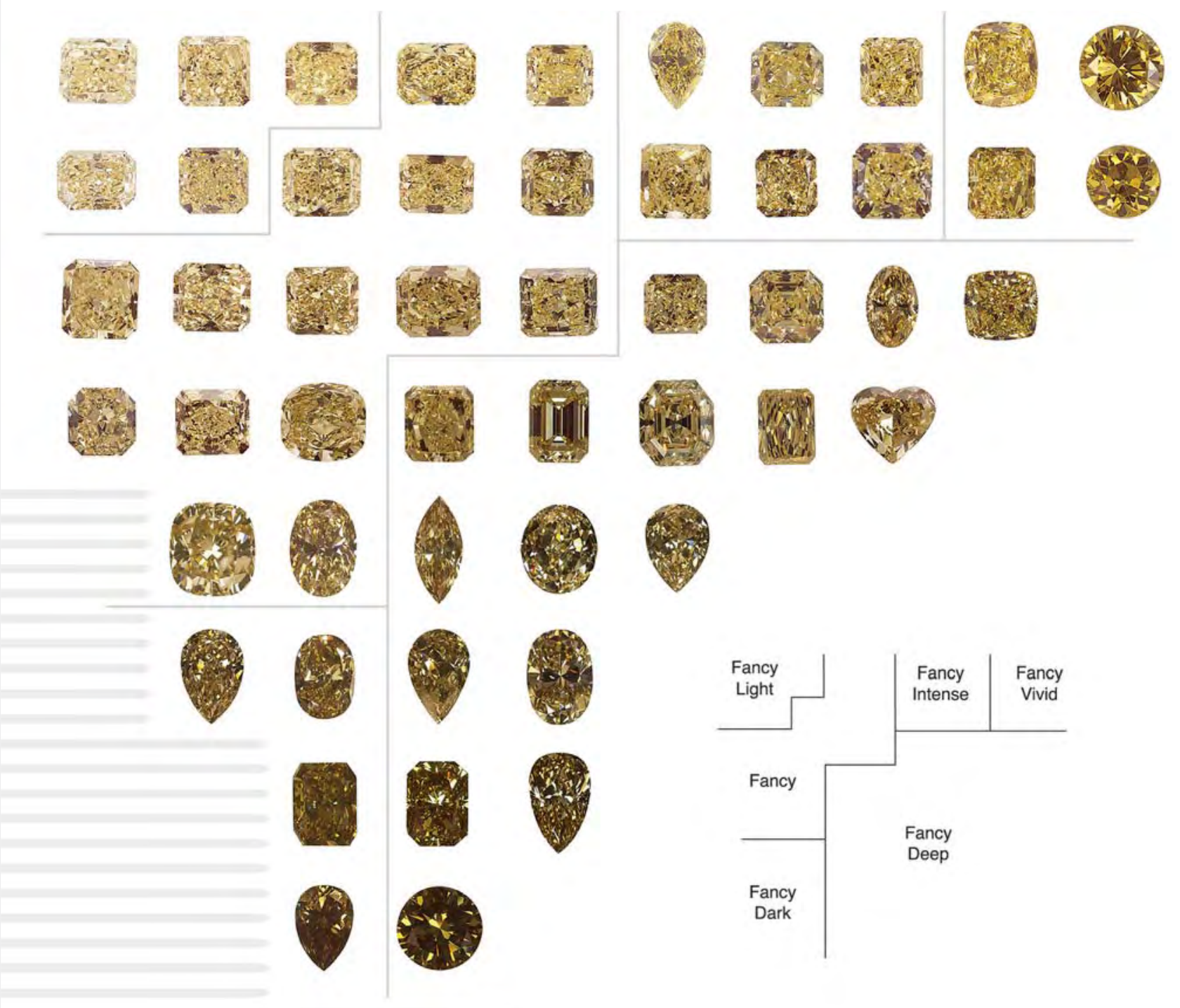

Figure 7. These two tone/saturation charts illustrate the color appearances at two locations in the yellow hue range: "warmer" yellow diamonds that lie toward the orangy yellow/yellow hue boundary, and "cooler" ones that lie toward the greenish yellow/yellow boundary. In each case, the lighter, more saturated colors are seen in the upper right of the diagram, whereas the darker, weaker colors are located toward the lower left. On each diagram, the inset chart shows the generalized boundaries of the GIA Gem Laboratory fancy grades. The shaded areas on the two charts indicate the areas in 


\section{"COOleR" Yellow}

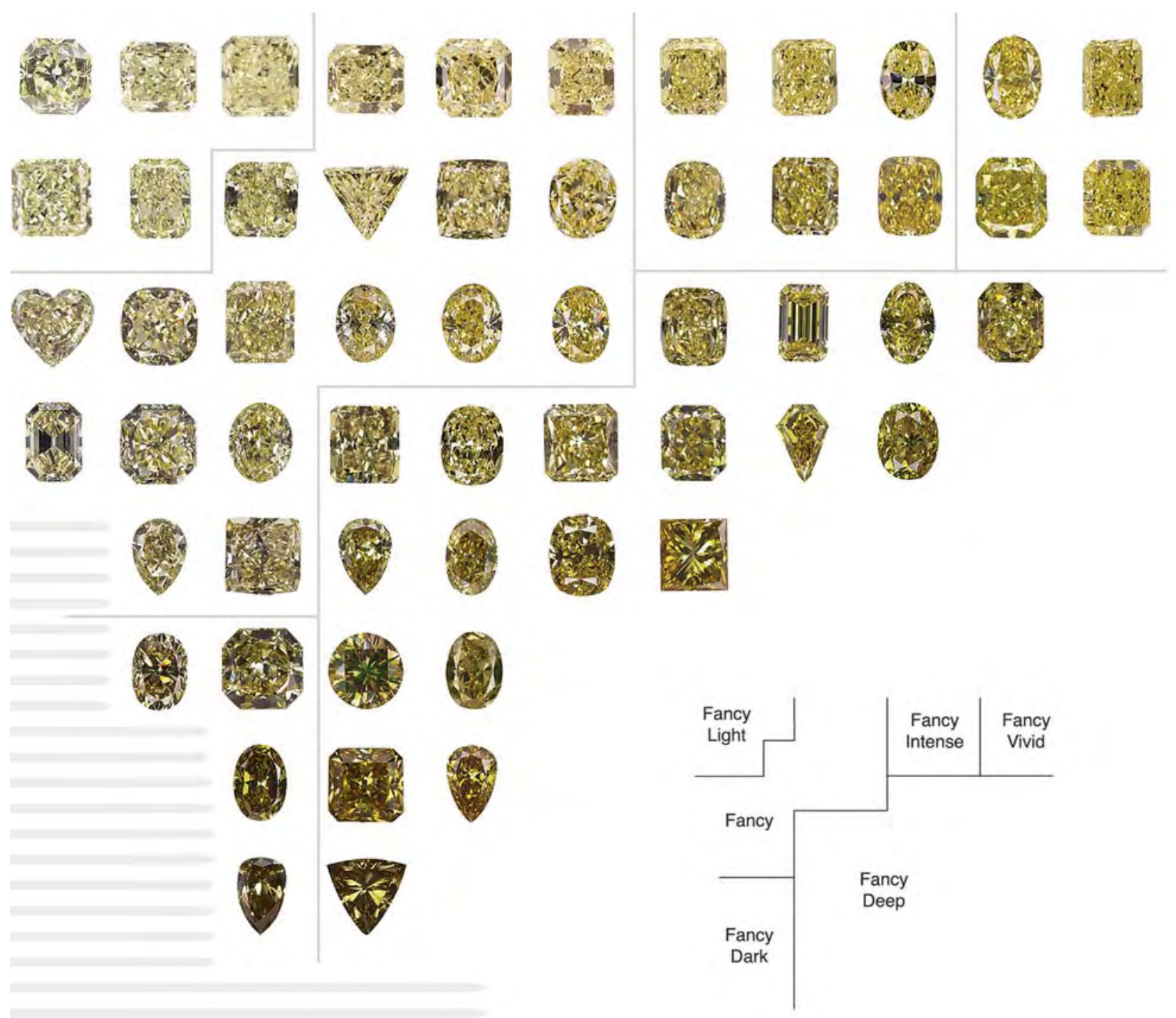

the yellow hue range in which diamonds described as predominantly brown (not part of this study) occur. Note that these two diagrams are for illustrative purposes only; by themselves, they are not adequate for use in color grading. Because of the inherent difficulties of controlling color in printing (as well as the instability of inks over time), the colors of the images shown here may differ from the actual colors of the diamonds. Photos by Elizabeth Schrader and C.D. Mengason. 


\section{DISTRIBUTION BY FANCY GRADE}
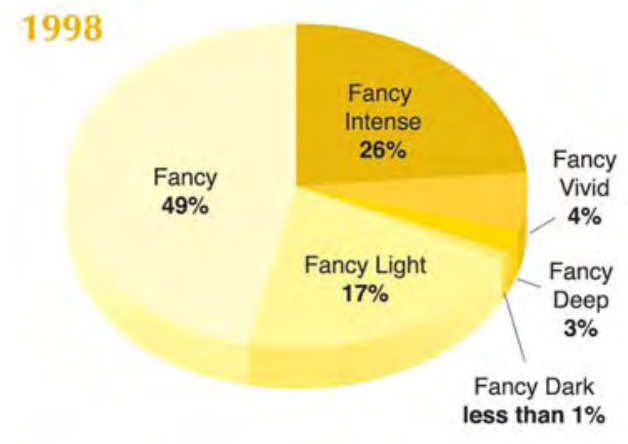

Fancy Dark less than $1 \%$

\section{3}

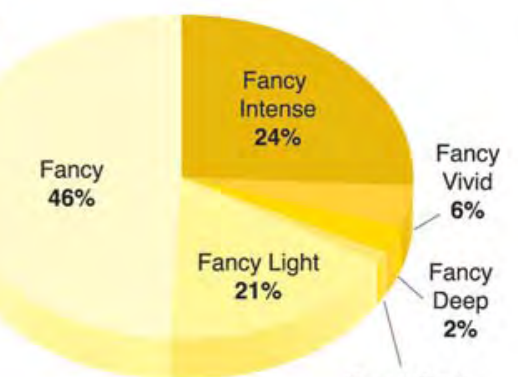

Fancy Dark less than $1 \%$
Figure 8. These pie charts show the percentages of the diamonds in the study in each of the GIA Gem Laboratory fancy-color grade categories for the years 1998 and 2003. Note the relatively consistent distribution between 1998 and 2003, even though requests for laboratory services more than doubled over this time period.

Figure 9. These Fancy Intense yellow diamonds illustrate four different positions within this color group. Members of the diamond trade sometimes describe those colors that lie near the yellow/greenish yellow boundary (like the diamond on the far right) as "lemony," and those near the orangy yellow/yellow boundary (as seen in the diamond on the far left) as "golden." Photos by Elizabeth Schrader.

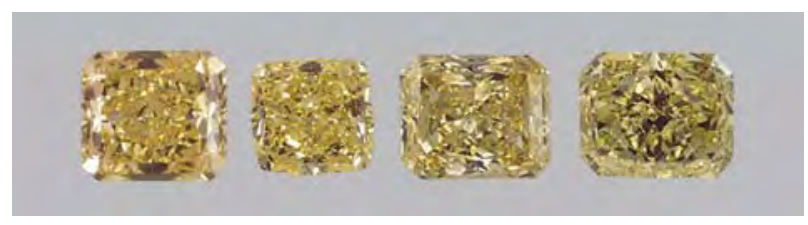

\section{DistRIBUTION BY CLARITY}

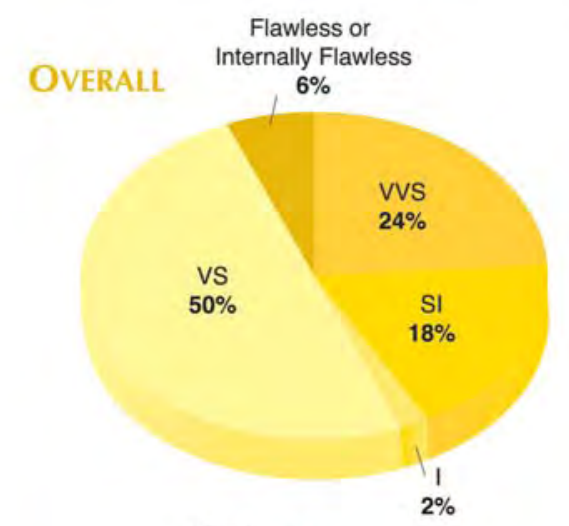

Flawless or Internally Flawless

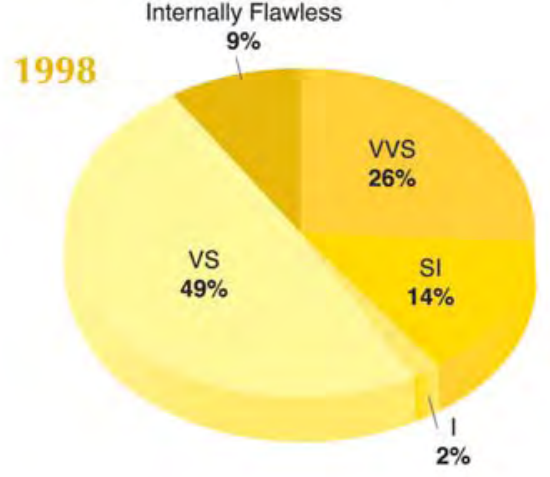

Flawless or

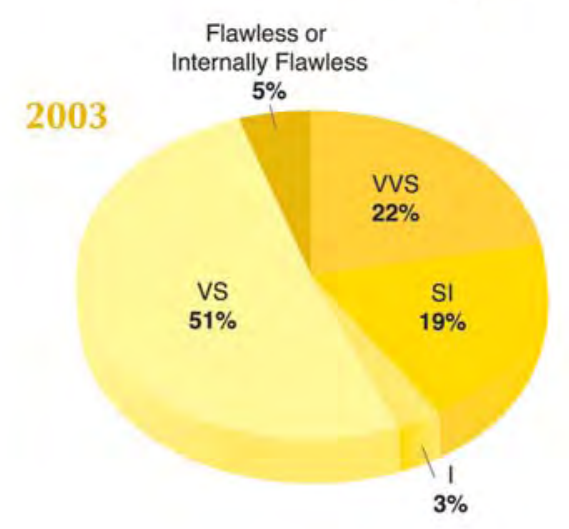

Figure 10. The diamonds studied were relatively high in clarity, with approximately $80 \%$ of the studied samples receiving grades of VS or higher. These percentage distributions were relatively consistent between the sample groups examined in 1998 and 2003. 


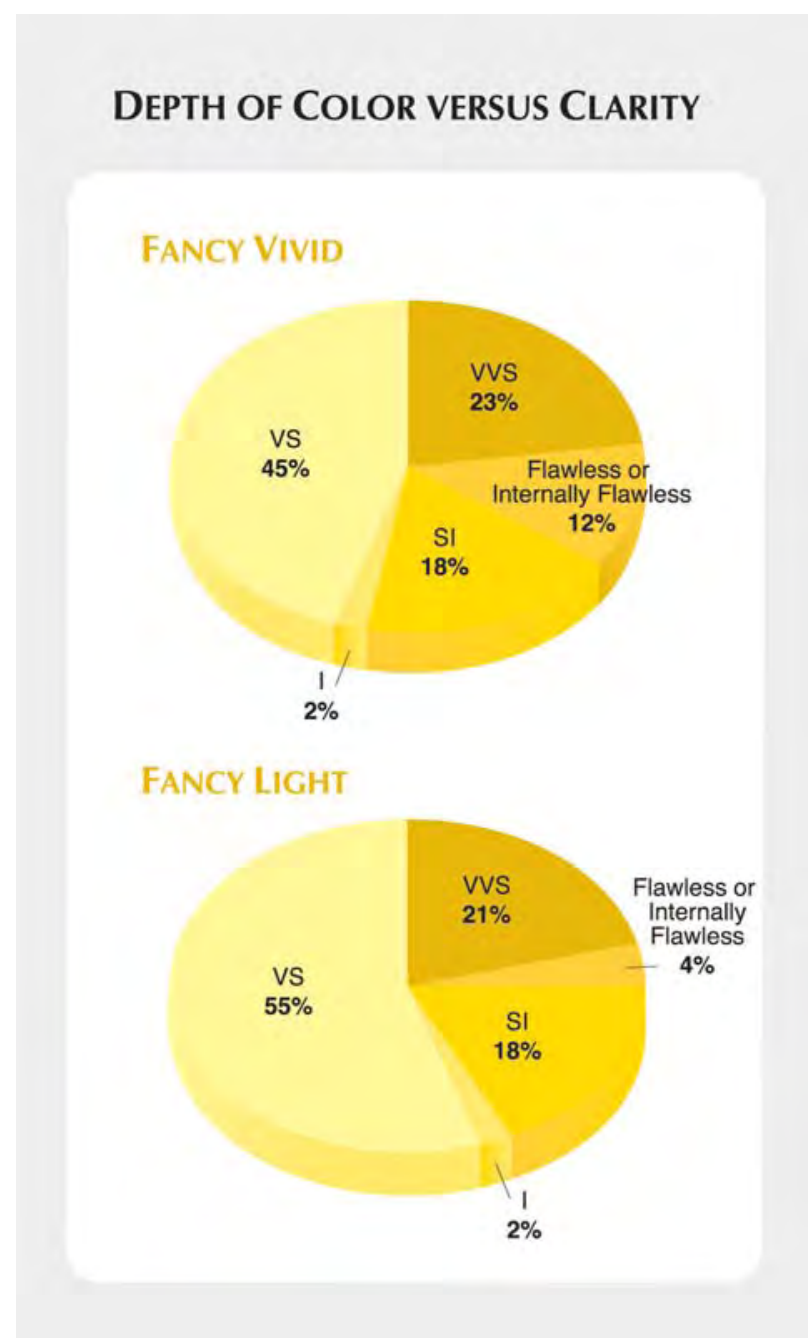

Figure 11. These two pie charts show the clarity grade distributions among those yellow diamonds in our total sample population with Fancy Vivid and Fancy Light color grades (which represent the extremes in yellow color saturation).

Graining. When observed under standard diamond grading conditions, the vast majority of the yellow diamonds did not exhibit typical forms of internal graining such as reflective planes or colored banding (i.e., whitish or brown). However, we found that one form of internal graining not commonly encountered in other fancy colors occurs more frequently in yellow diamonds. In this type of graining, the internal reflective graining plane exhibits a dispersion of color (figure 15) and maintains this appearance through a range of viewing angles. Because of the dispersive color appearance, this graining is described as "rainbow" graining; in some cases, it may affect the clarity grade.

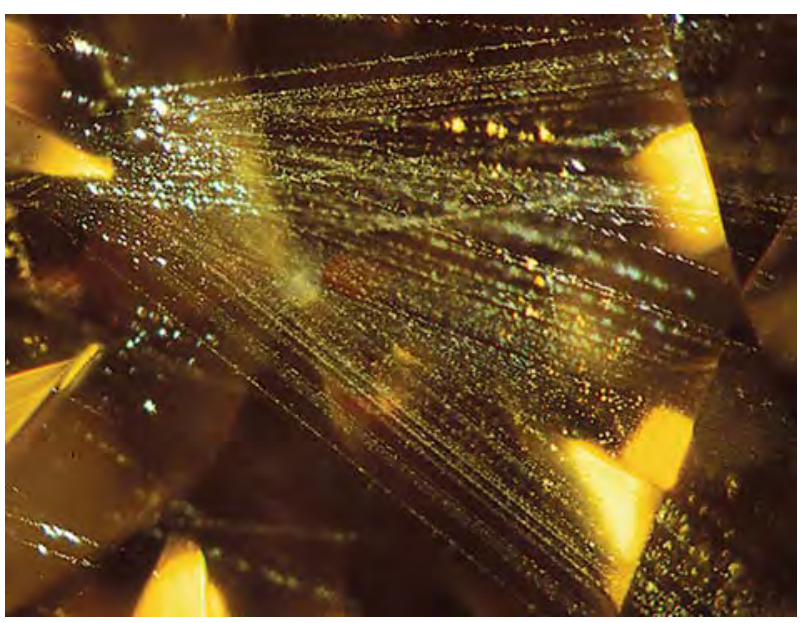

Figure 12. Stringers of numerous tiny inclusions, some in reflective orientation, create an interesting cloud formation in this brownish yellow diamond. The presence of this cloud further supports the diamond's natural-color determination. Photomicrograph by John I. Koivula; magnified 30x.

Color Zoning. Only 8\% of the diamonds in our study exhibited noticeable color zoning. When present, the zoning often took the form of diffused or concentrated patches of color (an appearance occasionally referred to as "scotch and water").

Ultraviolet Fluorescence. We found that $71 \%$ of our samples showed either no or a very faint reaction

Figure 13. Clusters of small black and metallic-looking needles and platelets, such as this triangular grouping, were seen in some of the yellow diamonds. These inclusions are probably composed of sulfides and graphite. The triangular form of this cluster suggests that it might also be a phantom plane.

Photomicrograph by John I. Koivula; magnified 25x.

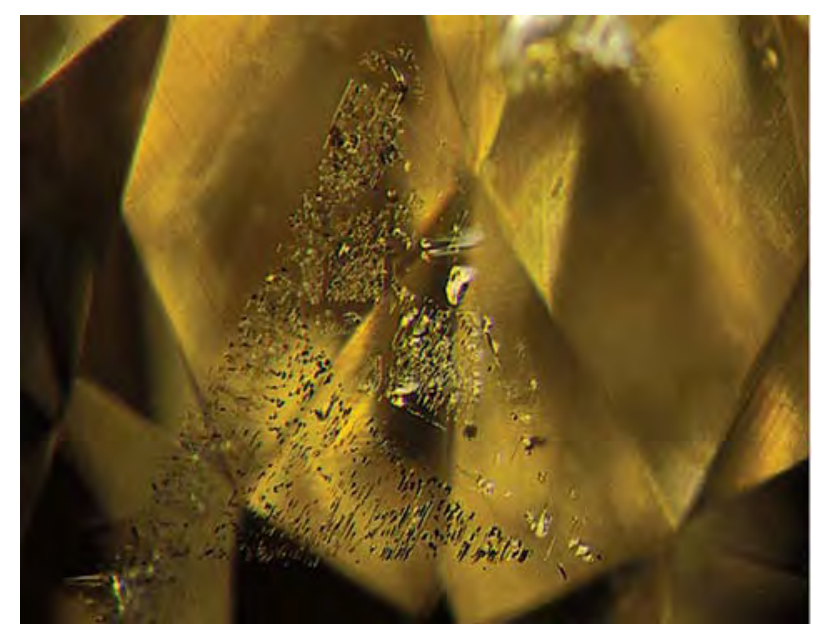




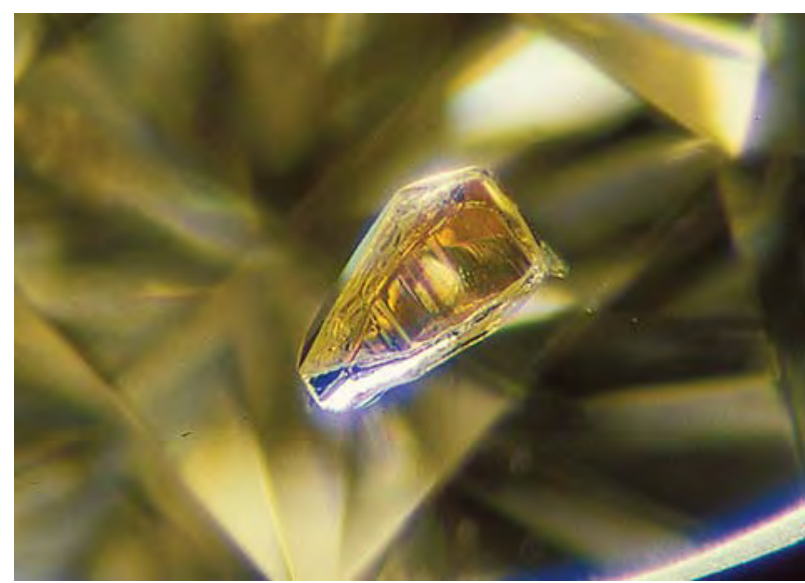

Figure 14. The most recognizable color for an eclogitic garnet inclusion in a diamond is orange. Such garnets are mixtures of almandine and pyrope. Their presence also provides proof of the diamond's natural origin. Photomicrograph by John I. Koivula; magnified 20x.

(both of which are referred to as "none" on grading reports) when exposed to long-wave UV radiation, while $25 \%$ displayed a faint to medium reaction. A

Figure 15. This 5.04 ct yellow diamond exhibits "rainbow" graining, a type of graining seen more commonly in yellow diamonds than in other colors. When this dispersion of colors remains visible through a range of motion, it can affect the clarity grade. Photo by Vincent Cracco; magnified 12x.

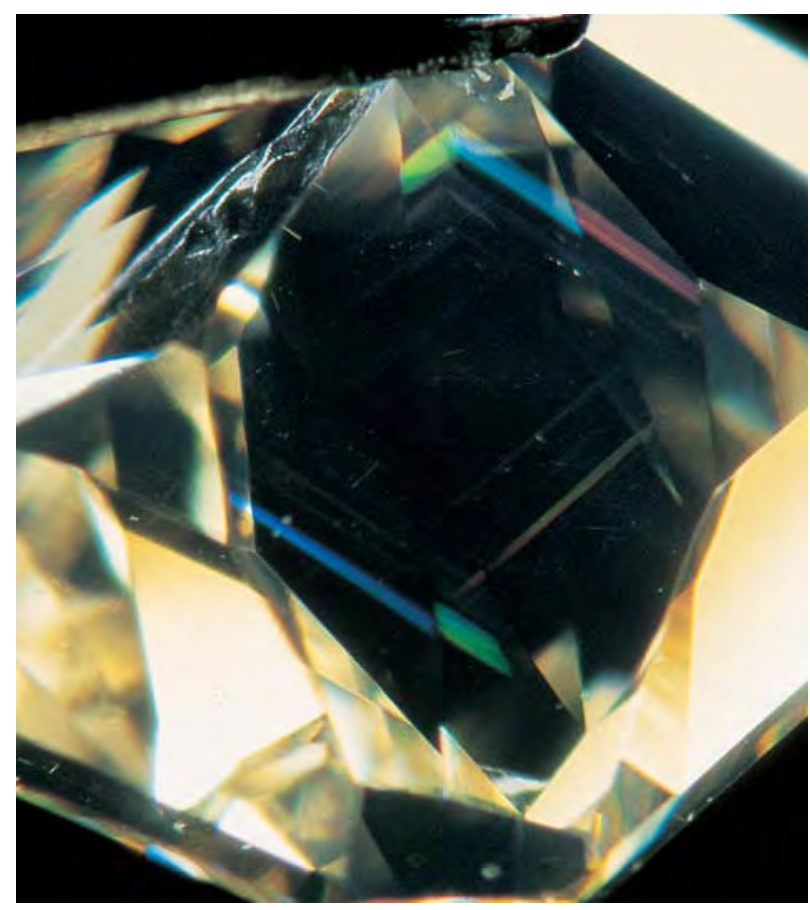

strong or very strong reaction was observed in less than $4 \%$ of the total group (figure 16). Of these latter samples, 92\% exhibited blue fluorescence, while the remainder displayed other colors (including green, yellow, orange, and white).

Eighty-eight percent of the samples displayed no reaction or a very faint to faint reaction to shortwave UV radiation. The remainder had medium $(11 \%)$ or strong reactions $(1 \%)$. In terms of their fluorescence colors, 91\% were yellow. The remainder fluoresced various other colors, but predominantly blue or green.

Spectrometry and Diamond Type Groups. Based on our subset of 10,399 diamonds, we found that type I yellow diamonds may be broadly categorized into five groups based on their UV-visible and infrared spectroscopy. Representative samples for each group are illustrated in figure 17.

Group 1. This first group represents the vast majority of yellow diamonds in the subset $(92.8 \%)$. Based on the intensity of features in their spectra, they demonstrated a high concentration of nitrogen and highly aggregated nitrogen impurities, consistent with type Ia diamond. Spectral features arising from isolated nitrogen were rarely seen in the samples in this group. The UV-visible and infrared spectra for a representative $1.31 \mathrm{ct}$ Fancy Vivid yellow diamond are displayed in figure 17A. The UV-visible spectrum is dominated by absorptions due to the N3 center, with zero-phonon-line absorption at $415 \mathrm{~nm}$ and its related sidebands with peaks at 376,384 , 394 , and $403 \mathrm{~nm}$. Other absorption features present-at 425, 438, 452, 465, and $478 \mathrm{~nm}$-are all related to the N2 center (Collins, 1982). The absorption features seen between 1400 and $1000 \mathrm{~cm}^{-1}$ of the infrared spectrum suggest high concentrations of aggregated nitrogen. Due to the completely radiation-absorbing nature of the type Ia nitrogen, spectral fitting could not be performed to calculate exact concentrations of nitrogen; however, these features suggest that this diamond has nitrogen concentrations of at least $200 \mathrm{ppm}$. Other spectral features characteristic of this group include a strong peak at about $1370 \mathrm{~cm}^{-1}$ associated with platelets-an extended defect composed of interstitial carbon and, possibly, nitrogen atoms (Collins, 2001) - and weak absorption peaks at 1547, 1520, and $1495 \mathrm{~cm}^{-1}$. At higher wavenumbers, weak peaks at 3236 and 3106 $\mathrm{cm}^{-1}$ are present, which are indicative of the presence of a trace hydrogen impurity (Field, 1992). 
Group 2. These diamonds comprise approximately $4 \%$ of the sample set, and they share many of the same nitrogen-related infrared and UV-visible spectral features as the diamonds detailed in Group 1. However, they differ significantly from the Group 1 samples due to strong absorption features related to hydrogen. This group is represented by a $1.26 \mathrm{ct}$ Fancy brownish yellow diamond. The infrared spectrum (figure 17B) displays high concentrations of type Ia nitrogen (similar to Group 1 diamonds) but clearly differs from them by features at 4495, 4168, 3236, $3106,2813,2785$, and $1405 \mathrm{~cm}^{-1}$-all related to hydrogen defects (Fritsch and Scarratt, 1992). The UV-visible spectrum also displays the N3 and N2 features associated with Group 1 diamonds, but it contains hydrogen-related absorptions at 474 and 563 $\mathrm{nm}$ - and two weak but broad bands at 545 and 555 $\mathrm{nm}$ - as well. Furthermore, a weak rise from a broad band resulting from a broad band center around 700 $\mathrm{nm}$ to longer wavelengths, possibly hydrogen related, is present (Fritsch and Scarratt, 1992).

Group 3. We found that $1.7 \%$ of the sample set fell into this group. These diamonds differed from all the other yellow diamonds because of their green luminescence to visible light. The 0.40 ct Fancy Intense yellow diamond seen in figure $17 \mathrm{C}$ is an example of this group. The UV-visible spectrum displays absorption due to the N3 center and weak N2related absorption features situated on a gradual rise at the blue end of the spectrum (which are collectively responsible for the predominantly yellow color). The weak green luminescence observed in these diamonds is a result of the $\mathrm{H} 3$ center (a defect consisting of two nitrogen atoms and a vacancy) at $503.2 \mathrm{~nm}$. The infrared spectrum suggests that almost all of the infrared active nitrogen is type $\mathrm{IaB}$, with a calculated total B-aggregate nitrogen concentration of more than $350 \mathrm{ppm}$.

Group 4. This group encompassed $0.8 \%$ of the sample set and is represented by a 2.03 ct Fancy Vivid yellow diamond. Unlike the other groups, the infrared spectrum (figure 17D) displays a relatively low concentration of nitrogen (calculated to be 16 ppm by means of spectral fitting). The nitrogen is mostly unaggregated $(\sim 11 \mathrm{ppm})$, and these predominantly type Ib diamond spectra exhibit a sharp absorption line at $1344 \mathrm{~cm}^{-1}$, and a broader peak at $\sim 1130 \mathrm{~cm}^{-1}$. A small amount ( $\left.\sim \mathrm{ppm}\right)$ of aggregated type IaA nitrogen, represented by an absorption at $1282 \mathrm{~cm}^{-1}$, is also present. Notably, the $1600-1450$

\section{FLUORESCENCE}

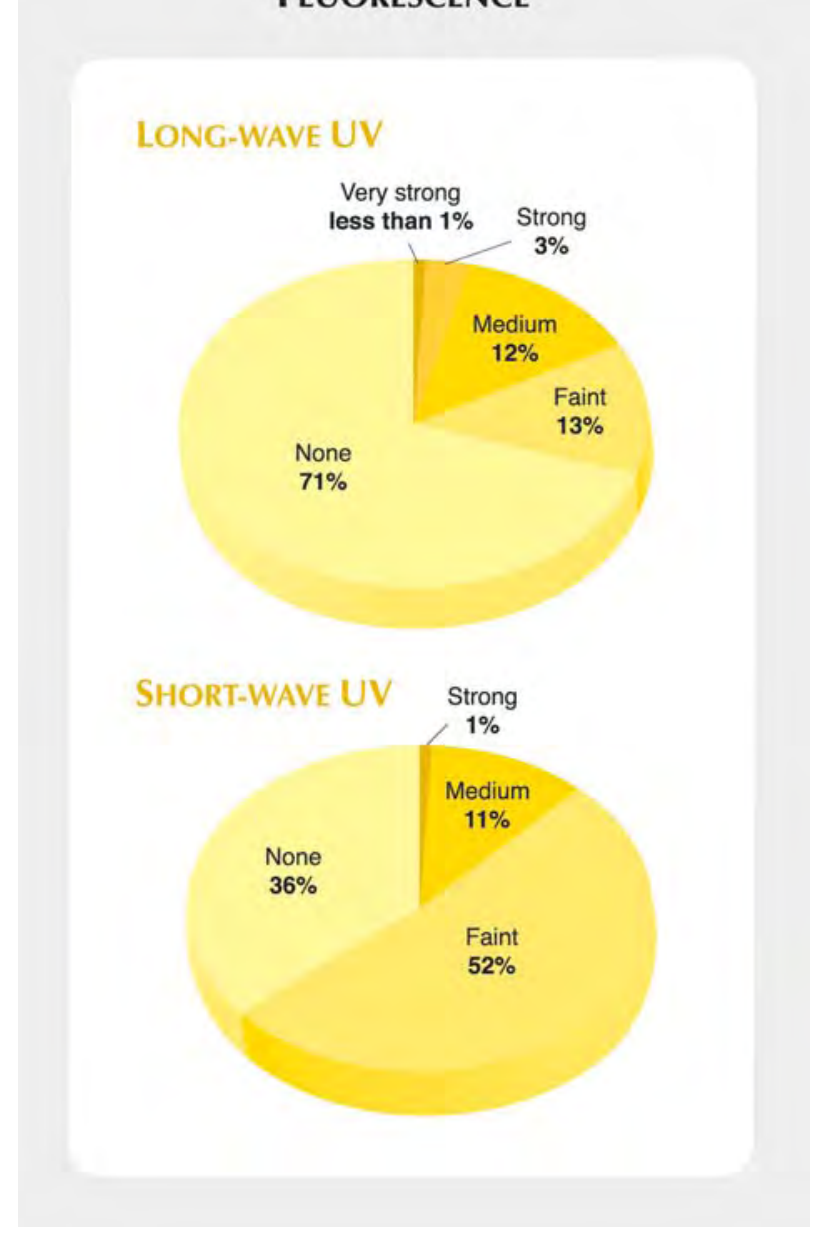

Figure 16. These two pie charts illustrate the strength of fluorescence of the studied diamonds to long-and short-wave UV radiation. In general, more than $80 \%$ of the samples displayed no fluorescence or faint fluorescence to both wavelengths. The most common colors observed were blue (92\%) for long-wave and yellow (91\%) for short-wave UV.

$\mathrm{cm}^{-1}$ region lacks any distinctive features. The visible spectrum is virtually featureless aside from a rise in absorption from $500 \mathrm{~nm}$ to shorter wavelengths. However, some diamonds in this group showed nitrogen-vacancy (NV) related absorption features at 575 and $637 \mathrm{~nm}$.

Group 5. The fifth group of yellow diamonds made up $0.7 \%$ of the sample set. It is represented by a 1.56 ct Fancy Intense yellow diamond. Absorption features related to N2 are generally much weaker than those in Group 1 for comparable color saturations. Similar to the samples in Group 4, the UV- 


\section{UV-VIS ABSORPTION SPECTRA}
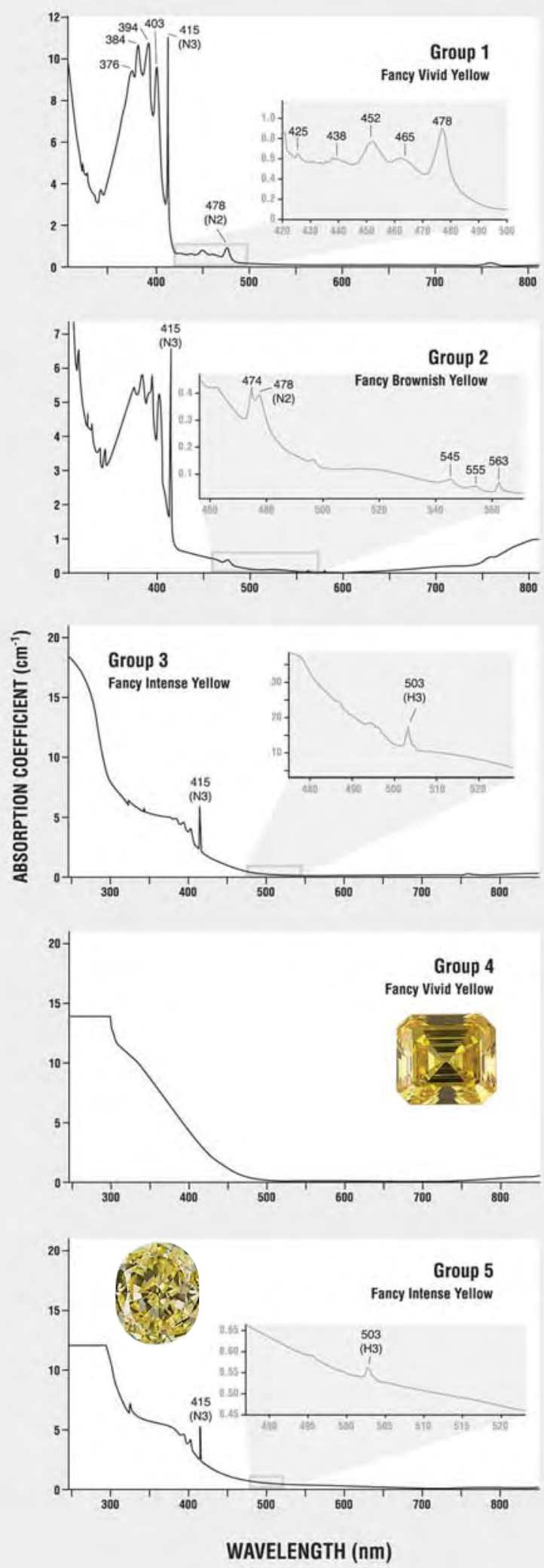

IR ABSORPTION SPECTRA

A
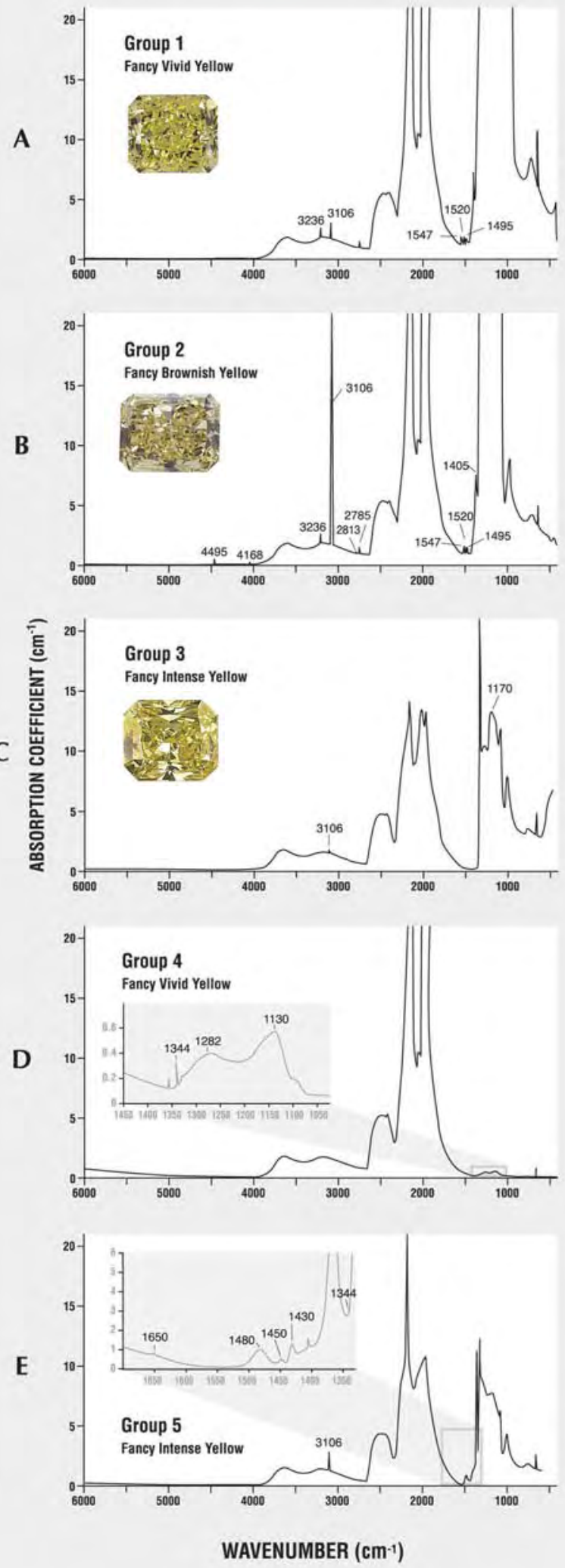
Figure 17A-E. Yellow diamonds may be broadly divided into five different groups based on their UVvisible and infrared spectra. One set of spectra for each of the five diamonds illustrated was chosen to represent the individual groups.

visible spectrum displays a gentle rise in absorption from $500 \mathrm{~nm}$ to shorter wavelengths, but with an obvious N3 zero-phonon line and its related sidebands. A weak $\mathrm{H} 3$ absorption was also observed. The infrared spectrum, like the spectra for diamonds in Groups 1 and 2, typically consists of totally absorbing type Ia nitrogen and the platelet peak. However diamonds of this group commonly had a broad absorption at $1650 \mathrm{~cm}^{-1}$; three absorptions at $\sim 1480,1450$, and $1430 \mathrm{~cm}^{-1}$ of varying sharpness; and, in many cases, a very weak absorption at $1344 \mathrm{~cm}^{-1}$ due to isolated (type $\mathrm{Ib}$ ) nitrogen (figure 17E).

\section{DISCUSSION}

Weight. With nearly one-third of our samples for both years of our study weighing more than $3 \mathrm{ct}$, it appears that the likelihood of encountering comparatively large yellow diamonds is significantly higher than for other colored diamonds, which typically occur in small sizes (see, e.g., Hofer, 1998; King et al., 1998, 2002). To confirm this, we looked at the average weight for colored diamonds submitted to the laboratory in the various hues in 2003. The average weight for yellows $(3.23 \mathrm{ct})$ exceeded that for all other hues and was more than one-third larger than the average for blues. King et al. (1998) indicated that $14 \%$ of the blue diamonds studied were over $5 \mathrm{ct}$, compared to $17 \%$ for this study. While these percentage differences do not initially appear great, the largest diamond in the blue study weighed $45 \mathrm{ct}$, whereas the present study included 23 diamonds over $50 \mathrm{ct}$ and three larger than $100 \mathrm{ct}$. Indeed, from our experience, no other colored diamond color occurs so consistently in such large sizes.

Cut. As discussed in previous studies (King et al., 1998, 2002), the primary goal of the cutter of colored diamonds is to enhance the final face-up color appearance. As shown by our data, yellow diamonds are typically cut as fancy shapes to help attain the most intense face-up color appearance. For a detailed discussion on manufacturing aspects of yellow diamonds, see box A.
Clarity. As with other natural-color diamonds, color is the primary factor in the valuation of yellow diamonds. Still, their relative abundance causes the diamond trade to seek additional means to differentiate among them, so the value placed on clarity is higher than for more rarely encountered colors (N. Livnat, pers. comm., 2005). This situation is evident in the shift in requests for specific GIA colored diamond reports between the two years of our study. Of the two colored diamond grading services offered by the laboratory, the Colored Diamond Grading Report includes clarity grading, while the Identification and Origin of Color Report (which focuses on the diamond's color information) does not. Requests for reports that included a clarity grade for the yellow diamonds described here increased from 57\% in 1998 to $75 \%$ in 2003 . The increased desire for more grading information (as represented by clarity grades) appears to parallel the increasing interest in yellow diamonds over this time frame.

Because a higher clarity grade can be a positive marketing factor, it is not unusual for a manufacturer to try to attain a minimum "VS" grade when possible (M. Witriol, pers. comm., 2005). Such an approach is consistent with the finding that $80 \%$ of the diamonds in our study were graded VS or higher. Manufacturers indicate that it is easier to attain a higher clarity grade with yellow diamonds than with diamonds in other colors because of the relative purity of some of the larger yellow rough (M. Witriol, pers. comm., 2005).

Interestingly, our data showed a percentage decrease for the clarity grade categories of FL/IF and VVS (from $9 \%$ to $5 \%$ and $26 \%$ to $22 \%$, respectively) between the two years of our study, but an increase from $14 \%$ to $19 \%$ for SI. We do not know if these changes in clarity grade distribution are a result of more requests for reports with clarity grades (from $57 \%$ to $75 \%$, as noted above), greater effort to quickly fill market need (i.e., manufacturers are working toward quicker turn-around rather than higher clarity), a change in the quality of rough being used, or a combination of these factors.

The analysis of clarity grade versus strength of color supported our assumption that there was little or no relationship between these two characteristics. As noted in our results, the distribution of clarity grades for Fancy Light and Fancy Vivid was similar, with the exception of FL/IF, where there were three times more diamonds in this category for Fancy Vivid than Fancy Light. The rarer a diamond's inherent color, the more likely it is that a manufacturer 


\section{Box A: The Importance Of Cut in Yellow DiamondS}

Manufacturing. Today, yellow diamonds (and colored diamonds in general) are typically cut as fancy shapes to enhance their color appearance (see figure A-1). It is not unusual for yellow rough to occur as octahedra (I. Wolf, pers. comm., 2005). The best yield and potential color retention for such crystals is found in square or near-square shapes such as radiants, emeralds, or cushions (which comprised as many as $61 \%$ of the samples in this study; see again figure 6).

Given the relative lack of inclusions and color zoning in large yellow rough, manufacturers can focus more on weight retention and color appearance (M. Witriol, pers. comm., 2004).

Cutting Innovations. Much of the framework on which today's cutting decisions are based originated with innovations begun in the 1970s. Previously, diamonds with light yellow bodycolor were manufactured in the shapes, cutting styles, and proportions of diamonds on the D-to-Z scale. Recent personal accounts to one of the authors (JMK) described how some of these changes came about (M. Blickman and J. Doppelt, pers. comms., 2005). By the mid-1970s, New York manufacturers such as Stanley Doppelt and Henry Grossbard had begun experimenting with variations on Basil Watermeyer's 1971 Barion cut, a square mixed cut whose step crown and modified-brilliant pavilion improved brilliancy and increased yield from the traditional step cut (see Kerr, 1982), in an attempt to hide imperfections in "cheap, square-cut diamonds." The assumption was that the increased scintillation from the mixed cut would better disguise inclusions, thus giving a more pleasing appearance to the eye. From an early point in this experimentation, Mr. Doppelt (and later Mr. Grossbard) realized these variations also enhanced the color of the yellow diamonds they were recutting, especially light yellow hues. Throughout the mid- to late 1970s, other experienced cutters experimented with the angles on these diamonds (from "offcolor" to noticeably yellow) to produce the best face-up color appearance.

In the late 1970s and early 1980s, the trade became aware of these potential cutting benefits. Mr. Doppelt, in conjunction with Louis Glick, introduced the "StarBurst" cut, which helped gain popularity for yellow diamonds. Mr. Grossbard, for his part, patented the radiant cut (Overton, 2002). Mr. Grossbard's 1976 purchase at Sotheby's Zurich of an off-color 109 ct diamond then named the Cross of Asia would eventually add to trade interest as well. He decided to recut that diamond to his new cut. Industry observers felt that the resultant $79 \mathrm{ct}$ Flawless, Fancy yellow renamed the Radiant Cut diamond was significantly more valuable than the original Cross of Asia (M. Blickman, pers. comm., 2005; this stone was graded prior to the 1995 modifications to the

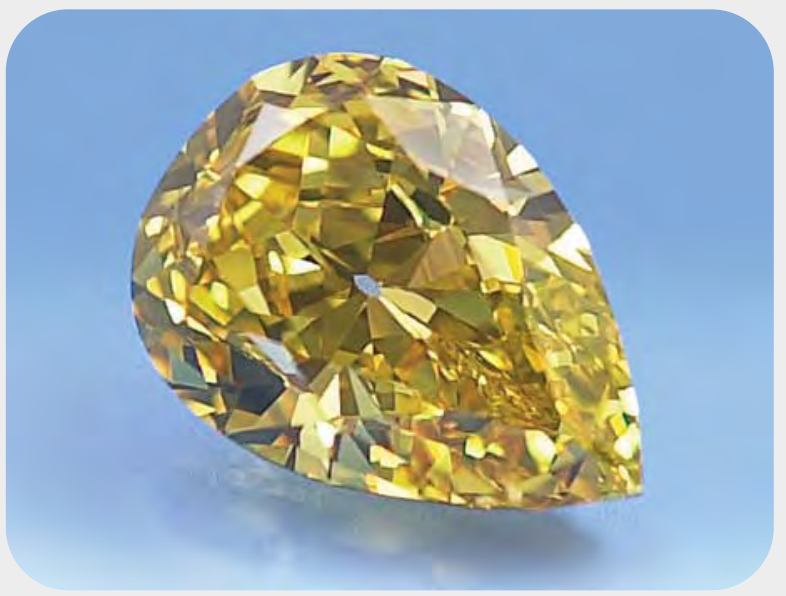

Figure A-1. This 10.12 ct Fancy Vivid yellow pear shape illustrates the effect a fancy shape can have on intensifying the color in a yellow diamond. Courtesy of the Scarselli family; photo by Elizabeth Schrader.

GIA colored diamond color grading system).

As others in the trade became aware of this recut diamond and the effectiveness of these new cuts in the market, more manufacturers began recutting light yellow diamonds into these styles in an effort to achieve grades of Fancy Light or Fancy (M. Kirschenbaum, pers. comm., 2004). Key features of these cuts were halfmoon facets on the pavilion, French culets, and a greater number of facets in general. The most dramatic differences in face-up color appearance were often seen when the starting material was a round brilliant (figure

Figure A-2. Some of the most striking differences are seen when a light yellow round brilliant is recut into a shape and cutting style, such as the radiant, that can accentuate the color appearance. For example, the 6+ct round brilliant diamond on the left was graded in the $W$-X range of the $D$ to- $Z$ scale. When recut as a $4.61 \mathrm{ct}$ radiant (right), it was graded Fancy yellow. Courtesy of the Scarselli family; composite photo by Elizabeth Schrader.
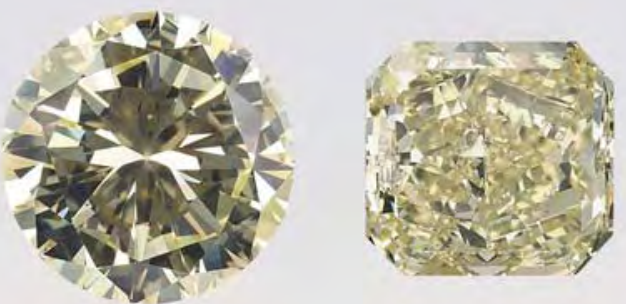


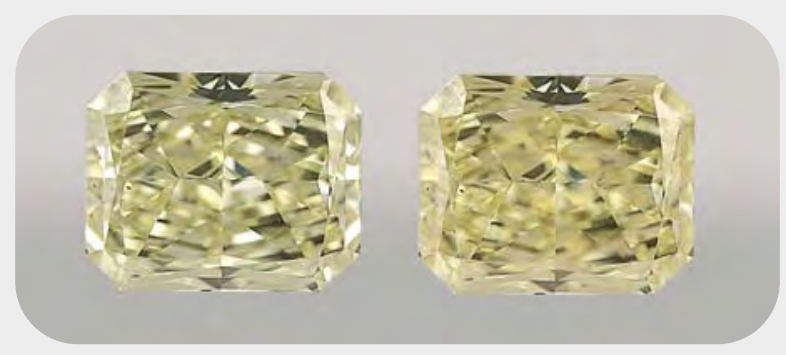

Figure A-3. Use of a diamond cut that highlights brightness can cause a light-toned yellow diamond to appear even lighter. The diamond on the left has numerous small, bright spots as a result of the manufacturer's cutting decisions. The one on the right is the same diamond with the spots digitally removed and replaced with the average face-up color. When the small bright spots are removed, the color appearance is subtly deeper (i.e., it appears slightly darker and stronger). If such a diamond were near a grade boundary, this subtle difference in appearance could move the diamond into a higher grade. Composite photo by Elizabeth Schrader.

A-2). Over time, the new shapes and cutting styles were used on diamond rough - a practice that resulted not only in better color grades but also in better weight retention, so manufacturing light yellow rough became more profitable (I. Wolf, pers. comm., 2004). Even more than the opening of new mines or a mine's increased production, these cutting activities were responsible for the greater number of more intensely colored yellow diamonds that appeared in the marketplace.

Effects of Cut on Yellow Diamond Color Appearance. As noted above, the appearance of light-toned colors is easily influenced by the effects of cut. Cutting can create brightness (white or near-white light return), fire (the dispersion of various colors), windows ("see-through"), and dark areas (extinction). Because colored diamonds are graded in the face-up position, the overall blend of sensations - small areas of brightness, windowing, and/or extinction-may intermingle with the yellow face-up color and affect the overall color appearance. For example, brightness can visually blend with color to cre- ate a softer, lighter appearance. If the color is near a grade boundary, such an appearance often results in the diamond being placed in a lower grade (i.e., with a weaker color; figure A-3). Similarly, small areas of windowing can mix with the color to create an overall washed out, weaker (i.e., less saturated) appearance. Overall darkness, or numerous dark areas due to extinction, can cause a "grayed-out," weaker look. Occasionally, these extinct areas can create a deeper appearance. Again, these effects can have an impact on color grade if the diamond is near a grade boundary.

Many diamond cutters are aware of the range of proportions that yield an attractive face-up cut appearance in colorless to near-colorless diamonds, but those who also cut colored diamonds often say "when it comes to color, you can throw away the book" (I. Wolf, pers. comm., 2005). An example of this is the rare Fancy Vivid yellow round brilliant in figure A-4. When observed by experienced staff and members of the trade, all agreed it was an exceptional color. But with a total depth of more than $65 \%$ and crown angles greater than $39^{\circ}$, it was unorthodox for a round brilliant and, if it had been near-colorless, would likely be considered less attractive than many other near-colorless diamonds. Clearly, the assessment of diamond cut for fancy-color diamonds is based on very different considerations than their D-to-Z counterparts.

Finally, cutting can also affect the perceived distribution of color when the diamond is viewed face-up. When the characteristic color does not predominate in the face-up position, it is reported as "uneven" for the "distribution" entry on grading reports (see King et al., 1994). Figure A-5 shows four examples of uneven color distribution in different shapes and cutting styles of yellow diamonds.

Figure A-4. With colored diamonds, cut is evaluated first in terms of its effect on the color. While this 1.51 ct Fancy Vivid yellow diamond has proportions that would be considered unorthodox for a colorless or near-colorless round brilliant, here they have produced a spectacular color appearance. Photo by Elizabeth Schrader.

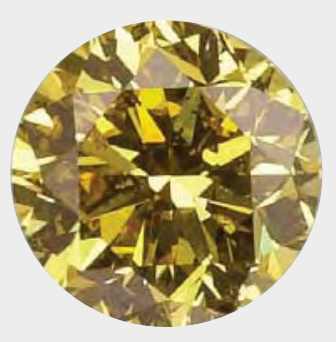

Figure A-5. In some diamonds, the yellow color can appear limited to a minority of areas relative to the total area in the faceup position. Such yellow diamonds would be described as having an "uneven" color distribution on GIA grading reports. As illustrated here, the appearance produced by this uneven distribution can vary depending on the cut and proportions used. Composite photos by Elizabeth Schrader.

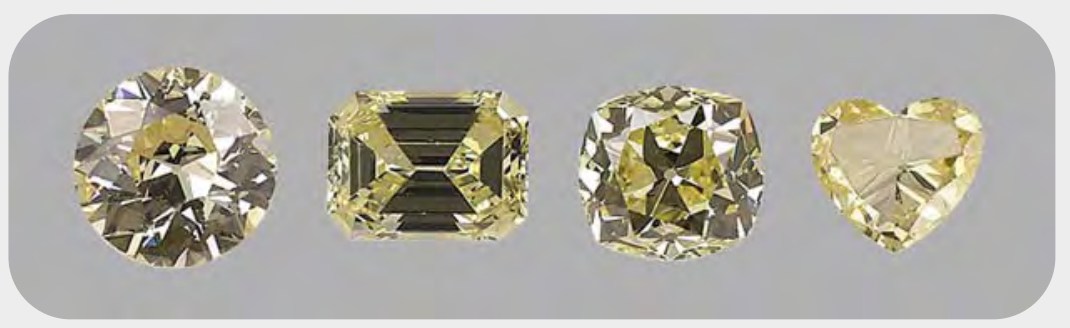


will consider working on other characteristics to further enhance its marketing potential (N. Smid, pers. comm., 2005). For the less-saturated colors, the manufacturer will factor in additional cutting (loss of weight), time costs, and current market salability into the decision to work toward the highest possible clarity. This approach is followed for colorless to near-colorless diamonds as well. It is much more likely for a manufacturer to try, when possible, to achieve a Flawless grade on a " $\mathrm{D}$ " color diamond than on a "K" color (N. Smid, pers. comm., 2005).

Inclusions. Given that the vast majority of the yellow diamonds in our sample group were type Ia, it is not surprising that their inclusions appeared to be the same as those encountered in diamonds on the D-to-Z scale (Koivula, 2000). Since the composition of these diamonds is essentially the same as those on the D-to-Z scale (differing only in concentration of defects), such a continuity of appearance would be expected.

Over the years, we have tracked the frequency with which pinpoint or small cloud-like inclusions occur toward the center of large (over $30 \mathrm{ct}$ ) diamonds submitted to the lab. A brief review of some of our historic records indicated that they were observed in more than half of 29 yellow diamonds weighing between 50 and 60 ct. The reason for this centrally located feature is not known, although these inclusions may represent growth conditions similar to those of symmetrical micro-inclusion "clouds" seen in other diamonds (see, e.g., Crowningshield, 1965). In our experience with yellow diamonds, the cloudlike inclusions may be distributed randomly throughout a stone, or they may follow specific growth sectors; in particular, cubic growth sectors $\{100\}$ tend to contain more clouds than any other sector (see, e.g., Wang and Mayerson, 2002). Occasionally, the clouds are very obvious and can affect the color appearance as well as the clarity grade. Although little is known about the chemistry and phase relations of the tiny clouds, with few exceptions high levels of infraredactive hydrogen (see below) were commonly detected by infrared spectroscopy in the regions where these clouds were concentrated.

Color Zoning. To see if there was a relationship between our overall findings $(8 \%$ of the samples exhibited color zoning) and the diamond type groups, we examined our subset of 10,399 diamonds for which type spectra were obtained. Most (92.3\%) of our type Ia yellow study diamonds (Group 1) did not exhibit noticeable color zoning. However, diamonds with different kinds of nitrogen aggregations (as evidenced by features in their spectra) had much higher occurrences of uneven color zoning. Specifically, $62.3 \%$ of diamonds that showed hydrogen absorption lines in their visible spectra (Group 2) had uneven color zoning, usually in the form of brown growth sector-related zones. In addition, $65.1 \%$ of diamonds that had green visible luminescence (Group 3) showed uneven zoning, which usually appeared as straight yellow lines paralleling internal graining. The type Ib diamonds (Group 4) showed color zoning in $56.8 \%$ of its samples, most commonly in the form of diffused zones or concentrated patches of color, occasionally referred to as "scotch and water." Unlike in other colors, such as type I pinks and type IIb blues where the zoning tends to form in discrete bands, the "scotch and water" zoning has less effect on manufacturing decisions with regard to orientation of the zoning in relation to the face-up appearance (I. Wolf, pers. comm., 2005). Like Group 1, the diamonds in Group 5 did not show noticeable color zoning.

Ultraviolet Fluorescence. Of the 10,399 diamonds studied for diamond type, only 75 showed a shortwave UV reaction that was stronger than the longwave reaction. Perhaps most interesting was that 58 $(77.3 \%)$ of these diamonds were type Ib. While not a conclusive test, this observation may be helpful to the diamantaire who does not have access to sophisticated equipment but wishes to have an indication of diamond type.

Spectrometry and Diamond Type Groups. As noted earlier, the yellow color observed in natural diamond is mainly a result of nitrogen, the most common impurity found in this gem. Both aggregated and isolated forms of nitrogen within the diamond's lattice are responsible for the unique absorption features in the blue portion of the visible spectrum, which in turn give rise to the yellow coloration. Variations in nitrogen aggregation that begin during diamond formation (as well as the addition of other trace impurities and other defects) lead to the differences seen in nitrogen-related spectral features.

The complex stages of nitrogen aggregation in diamond take place over geologic time at high pressures and high temperatures within the earth. During the initial stages of growth, nitrogen atoms may substitute for single carbon atoms within the diamond lattice. Diamonds containing isolated 
nitrogen are classified as type Ib (here, Group 4); they owe their unique "golden" yellow color to a rise in absorption from $500 \mathrm{~nm}$ to lower wavelengths (again, see figure 17D). In general, these yellow diamonds have low total nitrogen, even though their color is usually strongly saturated. As nitrogen-bearing diamonds continue to develop within the earth, the nitrogen atoms will migrate through the diamond lattice and over time may begin to form the commonly observed A, B, and N3 aggregates. Our spectroscopy results suggest that these optical centers are represented in the remaining four groups.

Group 1 diamonds contain a high concentration of N3 centers as well as N2 centers, which are attributed to a vibronic transition of the $\mathrm{N} 3$ center (Zaitsev, 2001). These are by far the most abundant yellow diamonds. Figure 18 shows overlain spectra of the Fancy Vivid yellow diamond in figure 17A and a Fancy Light yellow diamond also from Group 1. These spectra illustrate that the N2- and N3-related absorptions are stronger in the Fancy Vivid yellow diamond. Data from our entire subsample of diamonds on which spectra were taken suggest that the N2 centers in highly saturated yellow diamonds absorb more strongly than their less saturated counterparts; however, in many cases we observed that the N3 center in intensely colored yellow diamonds had the same absorbance as in their less intense counterparts. These data suggest that the $\mathrm{N} 2$ center plays a large role in determining the strength of yellow color saturation in Group 1 diamonds, as well as contributing to their "lemony" yellow color.

Group 2 diamonds are closely related to Group 1; however, our representative spectra for this group indicate high concentrations of hydrogen compared to Group 1 diamonds. Hydrogen-related absorptions in the UV-visible spectra may contribute to the modifying brownish and greenish appearances associated with these diamonds.

Similar to Groups 1 and 2, Group 3 diamonds contain aggregated $\mathrm{N} 3$ and $\mathrm{N} 2$ centers that contribute to the overall body color. In addition, however, Group 3 diamonds contain a green luminescence component that is attributed to small concentrations of another form of aggregated nitrogen, the $\mathrm{H} 3$ center, at $503.2 \mathrm{~nm}$. Group 3 diamonds also tend to contain significant concentrations of highly aggregated type IaB nitrogen. In fact, our infrared data suggest that the vast majority of the type Ia nitrogen in most yellow diamonds with H3-
UV-VIS ABSORPTION SPECTRA

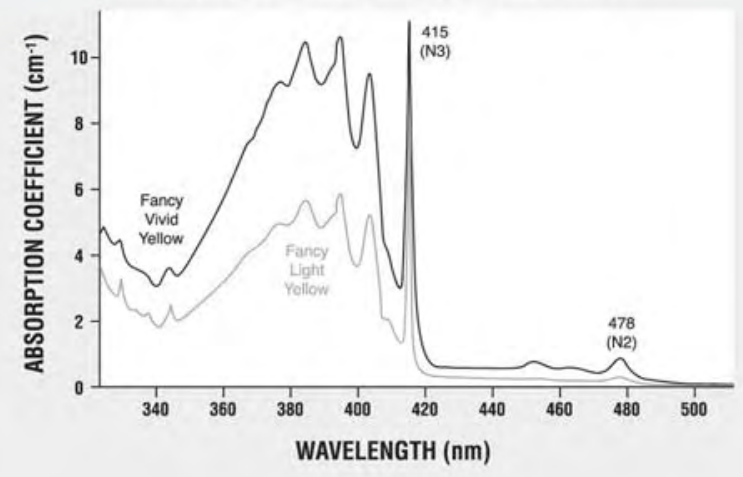

Figure 18. These two UV-visible spectra represent the Fancy Vivid yellow diamond from Group 1 (shown in figure 17A) and a Fancy Light yellow diamond from the same group. There are obvious differences in the strength of the N3 and N2 absorptions between these two diamonds of very different saturation.

attributed green transmission luminescence is in the form of B-aggregates.

As diamonds containing aggregated nitrogen mature in the mantle at elevated temperatures and pressures, it is possible that defects and nitrogen aggregates may begin to break up. Group 5 diamonds have spectral features similar to groups 1,3 , and 4, and some of these features may be linked to the destruction of defect centers and the disaggregation of nitrogen. The presence of the $1480 \mathrm{~cm}^{-1}$ peak in the IR spectrum has been linked to the degrading of the platelet peak at $1360 \mathrm{~cm}^{-1}$; other features at 1650,1450 , and $1430 \mathrm{~cm}^{-1}$ may also be platelet related and increase in intensity as the platelets are destroyed by increased annealing (Kiflawi et al., 1998). In addition, Group 5 diamonds typically show trace amounts of isolated (type $\mathrm{Ib}$ ) nitrogen, which suggests the breakdown of aggregated nitrogen after heating (Fisher and Spits, 2000).

Color Appearances as They Relate to the Diamond Type Groups. Despite the overlap, we did note different representative color appearances associated with the five groups. This can be seen in the photos accompanying the spectra of each group (again, see figure 17). The chart in figure 19 shows the general distribution of the diamonds in these groups in relation to the yellow fancy grades. The appearances associated with this larger distribution of tones and saturations can be seen when the areas noted in figure 19 are compared to the images in the corresponding locations in figure 7. 
The diamonds associated with Group 1 (more than $90 \%$ of our samples) have the appearance most commonly associated with yellow diamonds. In the stronger grades of Fancy Intense or Fancy Vivid yellow, these diamonds are often described as "lemony." Group 5 diamonds were similar in appearance to those in Group 1.

The green luminescence characteristic of Group 3 diamonds can be strong enough to affect the apparent color. However, the luminescence in our study samples was not noticeable enough under standard grading conditions to place the diamonds outside of the yellow hue range, although they were located toward the "cooler" side of that range (i.e., toward the yellow/greenish yellow boundary).

Group 2 diamonds often appeared brownish or had brown and green components, which may be due to the hydrogen-related absorptions in the UVvisible spectra. It is also likely that the spectral features of Group 4 diamonds (all type $\mathrm{Ib}$ ) are responsi-

Figure 19. While there are overlapping color appearances among the five "spectral groups" of yellow diamonds identified in our study, some areas are more representative of each particular group than the others. This generalized tone/saturation chart (with the fancy grades for yellow diamonds overlaid) illustrates the most common areas in which the diamonds in the five groups occur. ble for the strongly saturated, "warmer" yellow typical of these diamonds. Such "golden" color appearances are often associated with grades of Fancy Vivid and Fancy Deep yellow.

Color Appearance Transitions. As mentioned above, unlike other colors, the initial colored diamond grade associated with yellow is Fancy Light (again, see figure 7). The grade descriptions of Faint, Very Light, and Light are part of the D-to-Z scale, and they correspond to the K-M, N-R, and S-Z letter grade ranges, respectively (King et al., 1994). The transition in color appearance from these D-to-Z scale diamonds to fancy-color yellow diamonds is smooth, but the grading methodology and philosophy between the two scales changes abruptly.

A fundamental difference between these two grading scales is the value placed on "absence of color" in one (D-to-Z) versus "presence of color" in the other (colored diamond). The "absence of color" is primarily observed with the diamond in the table-down position, whereas the "presence of color" is only judged in the face-up position (King et al., 1994).

As the depth of color increases for diamonds on the $\mathrm{D}$-to-Z scale, the role of face-up observation (in addition to table-down viewing) also increases in importance during grading. The transition boundary between the D-to-Z scale and a fancy-color grid is the " $Z$ " grade. At this location, face-up appearance becomes the determining factor in assigning the color grade (i.e., a diamond must have a stronger face-up color appearance than the Z "master" to be considered a fancy color regardless of the bodycolor observed table down; figure 20).

Not only does methodology differ between these approaches, but the ranges of tone and saturation associated with a given grade are quite different as well. Grade ranges for fancy-color diamonds are significantly broader in both tone and saturation attributes than those on the D-to-Z scale.

In past observations, we have noted that some yellow color appearance transitions are more common than others, and this was supported by our data. The most common transition is throughout the saturation range rather than throughout tone or both tone and saturation. This is seen in the breakdown of our samples' fancy-color grades as well as their color descriptions. For example, about $97 \%$ of the diamonds in our study (representative of all diamonds in the yellow hue range submitted to the lab for 1998 and 2003) were Fancy Light, Fancy, Fancy 
Intense, or Fancy Vivid. All of these grades occur in a restricted tone range of medium to light, but they span the entire saturation range for yellow diamonds. Just as fancy grades are defined by related areas of tone and saturation in color space, some of the word descriptions (i.e., brownish or greenish) associated with them are also determined by their area of tone and saturation within the grades. Many color order/description systems (e.g., Natural Bureau of Standards, 1976), including GIA's, arrange their terms in color space to accommodate increasing appearances of brown or gray that occur as colors darken in tone and weaken in saturation. Since most of the yellow diamonds in our study were lighter in tone and of relatively strong saturation, they did not have a brown or green component. Understanding this ordering convention, and the occurrence of our samples in color space, clarifies why so few of the yellow diamonds in our sample $(5 \%)$ had descriptions of brownish yellow, brownish greenish yellow or brown-greenish yellow. It is understood, of course, that the GIA Gem Laboratory may not see the full range of yellow diamonds available. Nevertheless, given the large number of samples examined, this distribution may serve as a good indication of what goods are prominent in the marketplace.

Grade Distribution Over Time. It was interesting to note from our data that the distribution of fancy grades among our sample population was relatively consistent for the two separate years of our study. While far from being conclusive, these data give some indication as to the general distribution of yellow diamonds in that segment of the marketplace that uses GIA reports.

Figure 20. The transition from the D-to-Z scale to the fancy-color diamond scale for yellow diamonds is greatly affected by the cutter's ability to concentrate and intensify the face-up color, since it becomes the factor in determining the grade (not the "bodycolor" seen table down). In the diagram on the left, the $X$ marks the location of a yellow diamond that lies near the end of the D-to- $Z$ scale. The shaded area illustrates the range of potential tones and saturations and, in this case, grades the diamond could receive depending on how well the cutter was able to intensify the perceived face-up color. This is illustrated by the two yellow diamonds on the right. When observed table-down (top), both have a similar bodycolor.

However, when the same diamonds are observed face-up (bottom), the differences in appearance are obvious. While the table-down bodycolor of these two diamonds placed them near the end of the D-to-Z scale, their face-up appearances resulted in the one on the left being placed on the D-to-Z scale and the other being graded as a fancy color. Photos by Elizabeth Schrader.

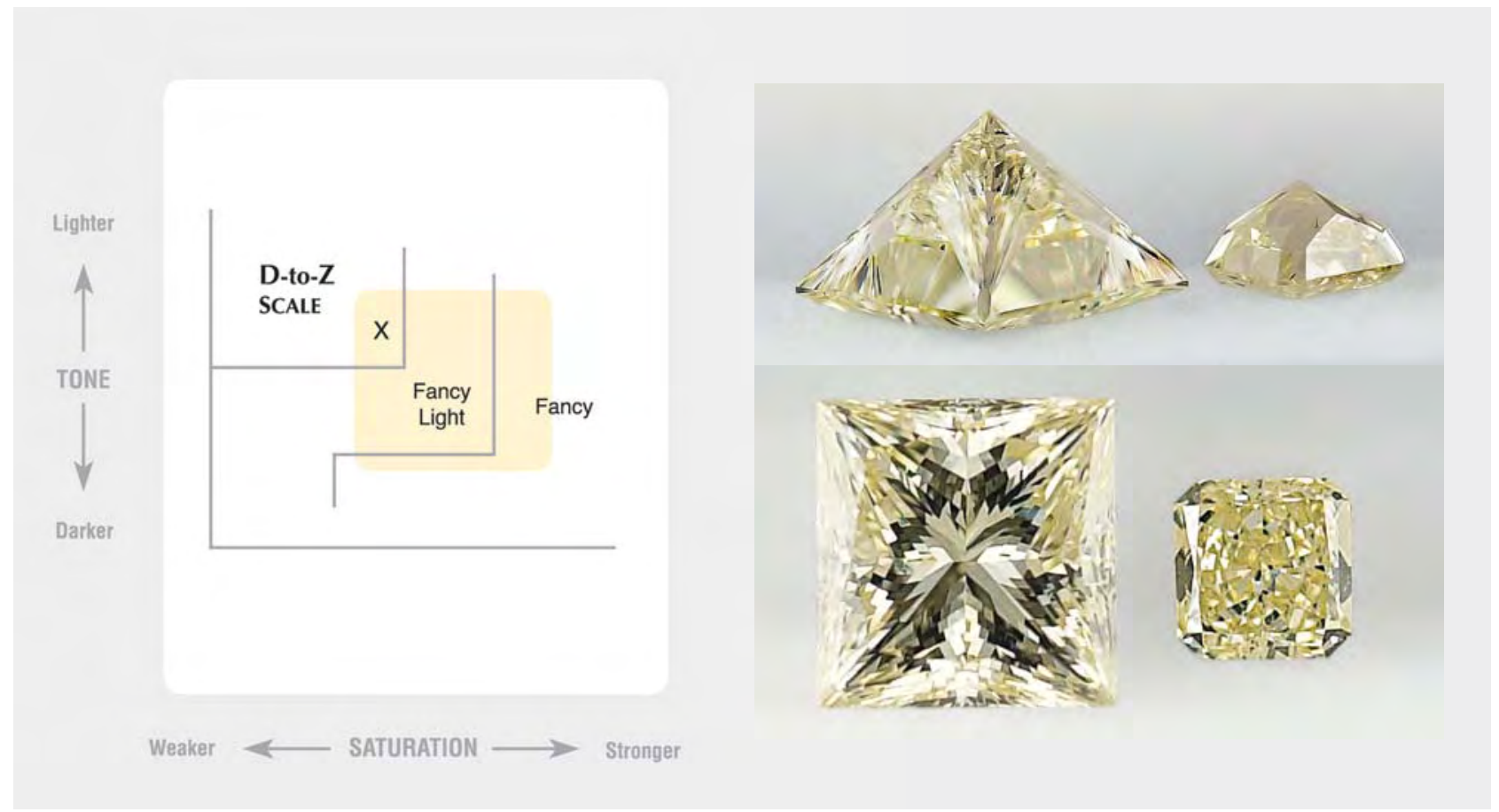




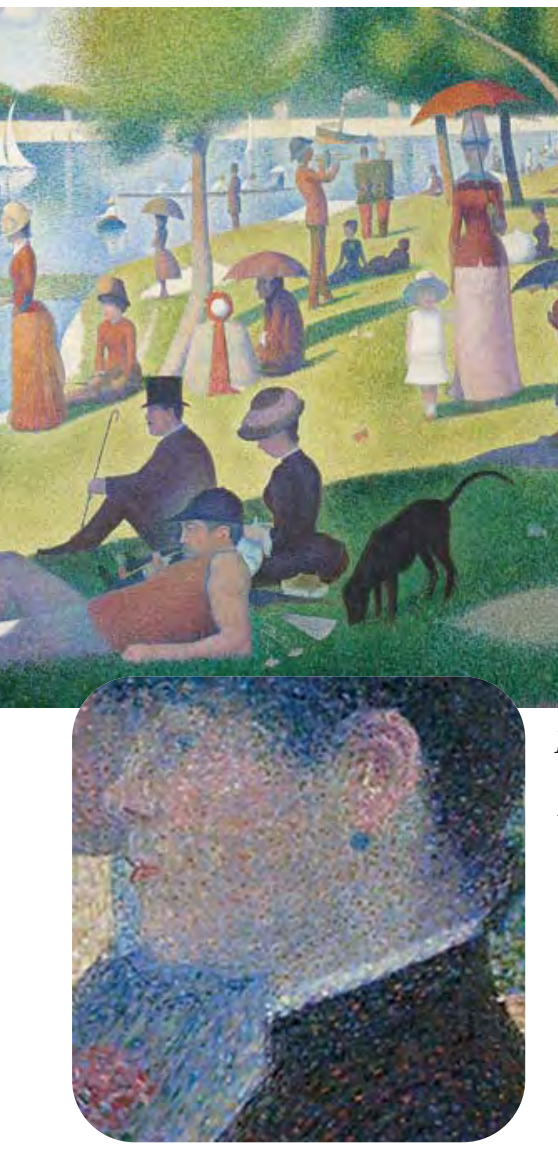
on La Grande Jatte, shows a number of distinct, individual colors; when the observer steps back and looks at the painting as a whole, these colors blend into a single color sensation. When grading a colored diamond, one can also pick out colors from a mosaic of appearances in the diamond, but the grade assigned is based on the overall blend. 1884, oil on canvas, $81^{31 / 44} \times 121^{11 / 44} \mathrm{in}$.; image courtesy of The Art Institute of Chicago, Helen Birch Bartlett Collection.

\section{A REVIEW AND ELABORATION OF FACTORS INVOLVED IN COLOR GRADING}

When GIA's colored diamond color grading system was first documented in this journal (King et al., 1994), we described our grading methods, environment, and terminology, to help those who use our reports understand the procedures and factors involved in assigning a color grade. Since that time, we have described the grading of blue diamonds and pink diamonds, specifically (King et al., 1998, 2002). Here, we would like to use yellow diamonds to review and elaborate on important aspects of color grading. From our discussions over the years, we have found that differences in grading interpretation can often be resolved by consistently answering two important methodology questions: (1) Where and for what is the grader looking when grading color in a diamond (i.e., observation)? And (2) how does that diamond relate to other diamonds in terms of color appearance (i.e., bracketing)?

Observation. As mentioned before, when observing a colored diamond, the face-up position is the only view used. However, even when restricted to the face-up position, differences between observers in the "plane of focus" can yield different results. This plane can be thought of as an imaginary surface parallel to the table facet where the eyes of the observer are focused to evaluate the color. Depending on the location of this plane-near the table facet, at a depth near the girdle, or even deeper within the pavilion of the diamond-an observer can reach different conclusions about the color. At the GIA Gem Laboratory, this plane of focus is located close to the table facet, not deep inside the diamond, so the grader observes the overall blend that constitutes the predominant single color appearance (i.e., the characteristic color).

Figure 22. A thorough understanding of yellow diamond color evaluation requires an awareness of the full range in which the color occurs. For example, when the Fancy Deep yellow diamond on the left is shown next to a Fancy Intense yellow diamond (top right), the color of the former appears darker and slightly less saturated, which some might consider less attractive. However, when the same Fancy Deep yellow diamond is shown next to a Fancy Dark brown-greenish yellow diamond (bottom right), the attraction of its rich yellow hue is more evident. Photos by Elizabeth Schrader.
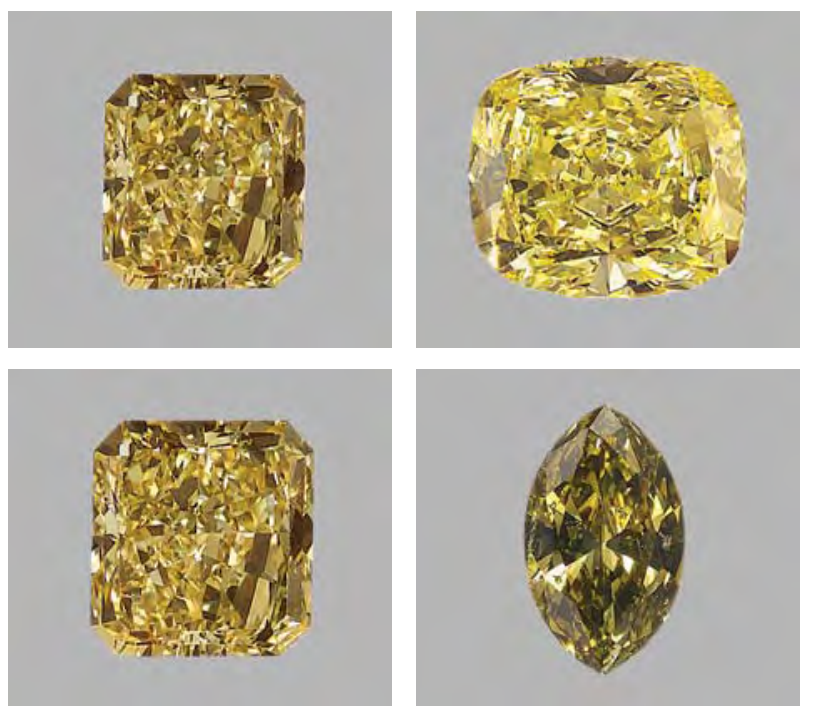

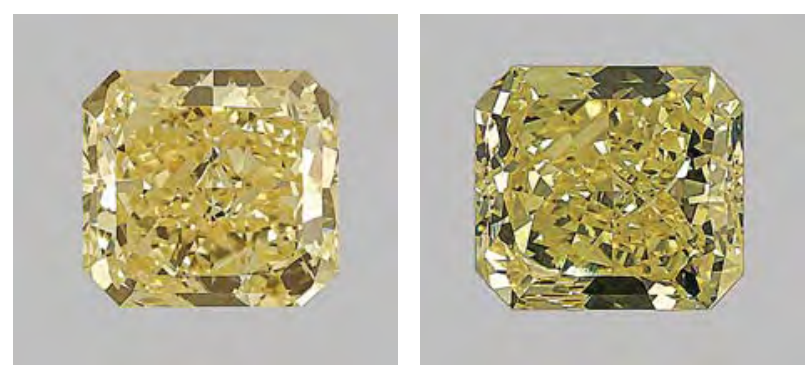

Figure 23. Yellow diamonds that lie near the yellow/greenish yellow boundary may appear less saturated if compared to a yellow diamond of similar strength that lies near the yellow/orangy yellow boundary. The two Fancy Intense yellow diamonds seen here are of similar saturation in GIA's grading system. To the inexperienced observer, however, the cooler yellow diamond on the right might appear weaker than the warmer one on the left. Photos by Elizabeth Schrader and C.D. Mengason.

Even with consistent lighting, environment, and viewing geometry, if one grader focuses deep into the diamond (or changes his/her focus to "pick out" highlights at different depths), it is possible to arrive at a conclusion different from that of another grader who is focusing on the table plane and observing the overall blend of face-up appearance.

The blended appearance that results from using a plane of focus near the table of a colored diamond can be likened to the merging effect that viewing distance has on color appearance in a 19th century pointillist painting such as Georges Seurat's $A$ Sunday on La Grande Jatte (figure 21), a commercially printed page (produced with very small dots of cyan, yellow, magenta, and black ink), or a checkerboard pattern. In each instance, more than one color is visible on close inspection, but they blend to a single overall color appearance when viewed at a distance.

Bracketing. Thorough bracketing of the characteristic color with color references of known location is crucial to understanding the grading of a colored diamond. This process allows the observer to understand the color's location in color space and the description related to that location. Without that understanding, proper evaluations may be lacking. For example, a diamond that appears darker and weaker when compared to lighter, stronger reference diamonds (figure 22, top) will appear rich in color when compared to its darker and weaker counterparts (figure 22, bottom).

Bracketing is also important to accurately grade yellow diamonds of similar tone and saturation but at opposite ends of the hue range. The appearance of those toward the "cooler" end of the range is different from those at the "warm" end, and this difference may be confused with strength of color if the diamond is not compared and bracketed consistently (figure 23).

Because yellow diamonds commonly transition in color appearance through a relatively narrow range of lighter tones, it is easy to misinterpret those falling outside that norm. To prevent this, observers need to be aware of the appearance relationships seen throughout the complete tonal range. Unless compared to known samples, the saturation of less commonly encountered colors of darker tone may be considered stronger than they are (figure 24). For example, the difference in appearance between a typical Fancy Light yellow diamond and one that is

Figure 24. If a diamond is near a grade boundary, darker tone can be confused with increasing saturation if known references are not used. Here, two examples illustrate this situation. On the far left are three diamonds near the Y-Z/Fancy Light yellow saturation boundary; the diamonds are of similar saturation and differ only in tone. Comparison to the Fancy Light yellow reference diamond to their right establishes their grade on the D-to- $Z$ scale. On the right, a similar situation is seen with three diamonds near the Fancy Intense/Fancy Vivid boundary; their Fancy Intense grade is clear when they are compared to the Fancy Vivid yellow reference diamond to their right. These tonal differences can be misinterpreted by an inexperienced observer. Photos by Elizabeth Schrader.

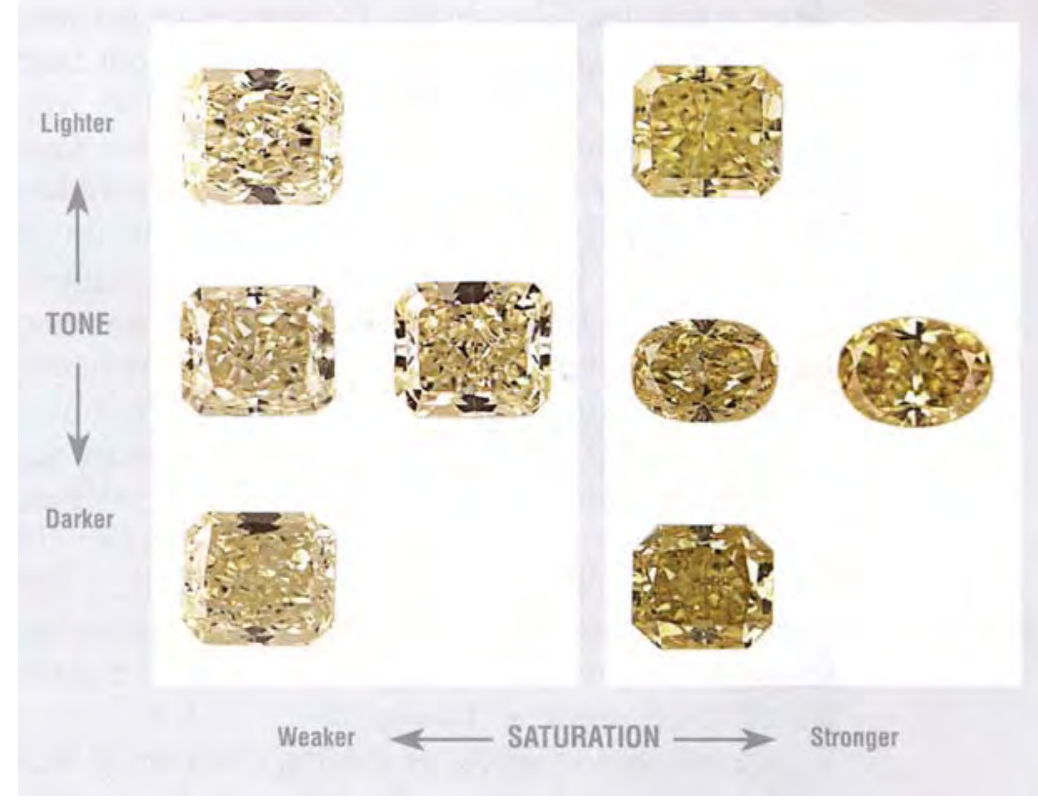



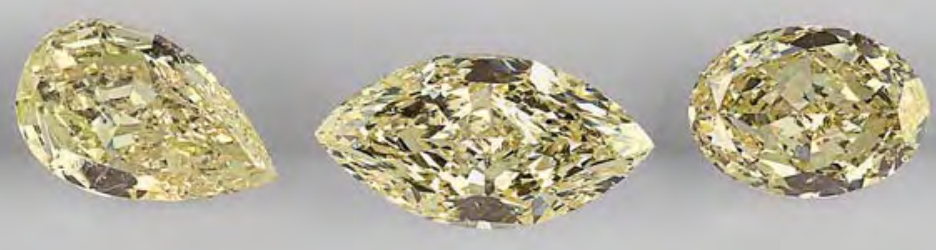

Figure 25. The light-toned yellow diamond shown in the center appears to "stand out" relative to the other two diamonds. Nonetheless, all three diamonds have the same Fancy yellow color grade. Photo by Elizabeth Schrader.

darker toned might lead to the incorrect assumption that there is a difference in saturation, and hence to the diamond being graded Fancy yellow. Similarly, fancy-color yellow diamonds that are light in tone often appear to "stand out"' from darker diamonds of similar hue, resulting in the misinterpretation of a "higher" grade. Lightness does not necessarily mean they are stronger or weaker in saturation and therefore fall into a different grade (figure 25).

Even though saturation-based grade transitions are relatively common among yellow diamonds, the observer may not know the full range of appearances within a grade, especially since grade ranges are quite different from those on GIA's D-to-Z scale. One can incorrectly assume that two yellow diamonds near the upper and lower boundaries of a grade's saturation range are in different grades if the entire range is not understood.

A number of the examples above illustrate the fact that there is a different appearance associated with each transition step in each one of a color's three attributes. The change in appearance between a tonal step (lightness to darkness) is different from that seen in a saturation (strength of color) step. Similarly, a transition in hue appears different from one in tone or saturation. Without understanding the difference between these appearance transitions, it is difficult to locate one color in relation to others. The process is further complicated by the complex face-up appearance of diamonds. In our experience, by working consistently with known references (and, preferably, the same references), a grader can develop an understanding of the appearance relationships between them and consistently interpret the transition. Changing references may result in less consistency because the observer risks misinterpreting an attribute in the changed reference that is not the determining factor for a grade.

An interesting aspect of grading observation that occurs at the laboratory but is more common in the marketplace is the occasional need to make a general assessment of a diamond's color while it is in a jewelry mounting. The appearance of yellow diamonds may be influenced by jewelry mountings to various degrees, as the color of the metal (especially yellow gold) can affect the apparent color of the diamond. It is important to keep this in mind when making color comparisons. At the laboratory, we follow our standard grading methodology when grading colored diamonds mounted in jewelry, but we assign a more generalized, multiple grade range for the diamond. Figure 26 shows a loose diamond that was near the Y-Z, Light yellow/Fancy Light yellow grade boundary before it was mounted (top) in an $18 \mathrm{~K}$ gold ring (bottom). The color appearance of the diamond when mounted was well within the Fancy yellow range; depending on the cut, this effect can be more or less pronounced.

Figure 26. The color of most yellow diamonds may appear noticeably darker and stronger when set in a mounting. The diamond on the left in the top image is near the Y-Z, Light yellow/Fancy Light yellow boundary and is shown next to a Fancy yellow reference diamond. In the bottom image, the larger diamond is mounted in a ring and placed next to the same reference diamond. While the jewelry designer can use these effects to enhance the appearance of a yellow diamond, it is important that the observer be aware of this difference when evaluating the color of mounted diamonds. Courtesy of the Scarselli family; photos by Elizabeth Schrader.
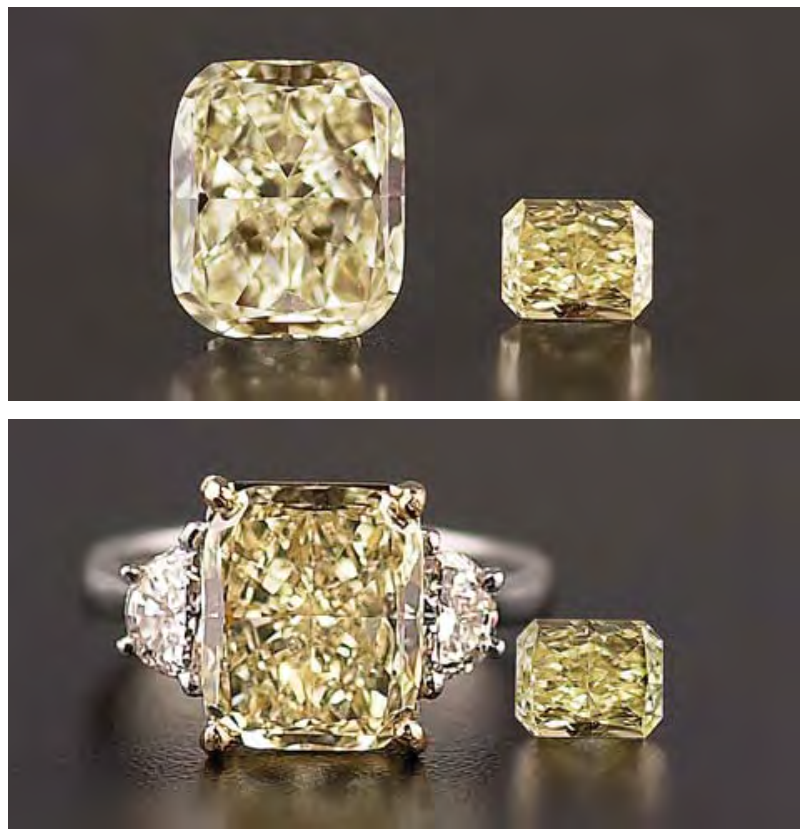


\section{SUMMARY AND CONCLUSIONS}

Yellow diamonds occur in a wide range of tones and saturations, but the majority encountered in the industry fall into the saturation range represented by the grades Fancy Light, Fancy, Fancy Intense, and Fancy Vivid. Yellow diamonds occur in some of the highest levels of saturation we have seen in colored diamonds to date. The fact that they also occur in larger sizes than other colored diamonds offers greater versatility for the jewelry designer (figure 27). With clarity grades that are commonly "VS" or higher, the manufacturer is often able to cut to proportions that offer maximum weight yield and the most intensified face-up color appearance without requiring as many modifications for clarity characteristics as with other colors. An important manufacturing consideration with yellow diamonds is that the lighter tones are more readily affected by cutting decisions than darker, deeper colors. Brightness, windows, and extinction can affect the grade if the color is already near a grade boundary. Understanding the effect of jewelry mountings on the color is also important for the designer or laboratory/jewelry professional who needs to evaluate yellow diamonds when mounted.

Many of the routine manufacturing decisions used for colored diamonds today had their roots in the cutting innovations first seen with yellow diamonds in the 1970s (again, see box A). Early experiments with cut variations employed to hide inclusions were found to also intensify the face-up appearance of light yellow diamonds. Soon these techniques were applied to a broader tone and saturation range of yellow diamonds and, eventually, other colors.

While it is difficult to define groupings within type

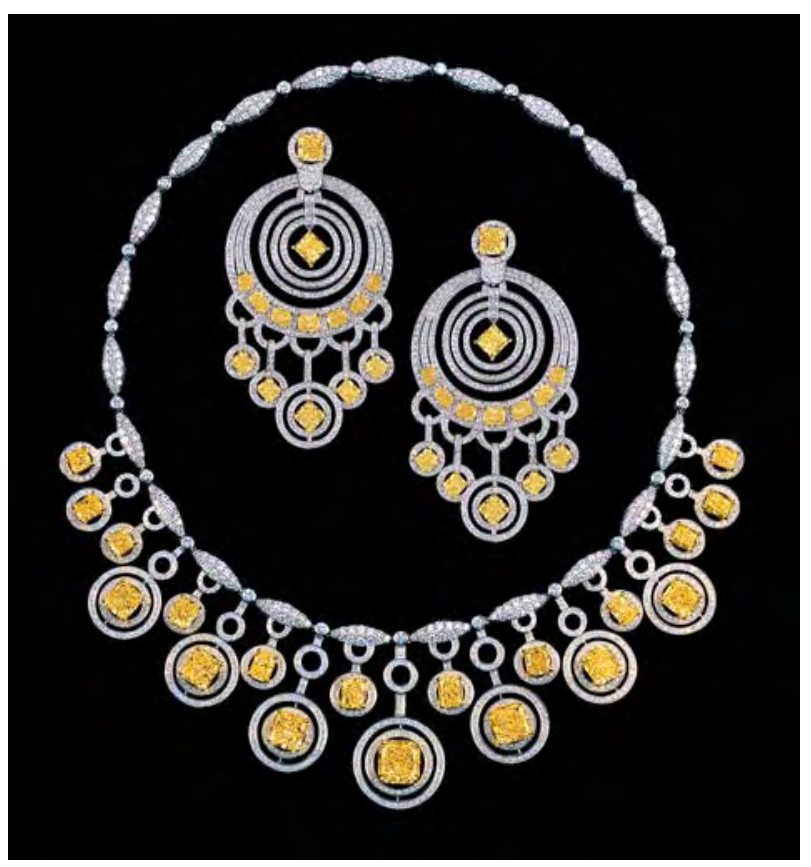

Figure 27. Increasing numbers of yellow diamonds are appearing in haute couture jewelry, as seen in these Gypsy earrings and the Bull's Eye necklace. Composite photo courtesy of Graff Diamonds.

I yellow diamonds due to the many overlapping spectral features, we were able to establish five groups with distinct spectral characteristics. We have shown the spectral relationships between these representative groups within yellow type I diamonds and noted a general relationship of these groups to color appearance.

An important goal of this study was to provide a better understanding of the range of color appearances associated with yellow diamonds. Understanding this range will help the growing number of traders in yellow diamonds evaluate these diamonds properly.
ABOUT THE AUTHORS

Mr. King is laboratory projects officer, Mr. Gell is staff gemologist, Mr. Hall is manager of analytical research services, and Dr. Wang is research scientist at the GIA Gem Laboratory in New York. Dr. Shigley is director of research, and Mr. Guhin is grading lab manager, at the GIA Gem Laboratory in Carlsbad, California.

ACKNOWLEDGMENTS: The authors thank the following individuals for providing information on the geologic occurrences of yellow diamonds: Dr. Jeff Haris of the Geology Department at the University of Glasgow, Scotland, and Dr. A.J.A (Bram) Janse of Archon Exploration Pty Ltd. in Perth, Australia. Kim Cino and Jacquelyn Haahr at the GIA Gem Laboratory in Carlsbad assisted with the Horizon computer management system retrieval of data on yellow diamonds. Tom Moses of the GIA Gem Laboratory in New York provided insights throughout the development of this article. Joshua Cohn and Akira Hyatt, both also with the GIA Gem
Laboratory in New York, provided helpful discussions and coordination of diamond selections for the various images, and assisted with the selection and appearance relationships of the colored diamond images, respectively. John Koivula, formerly of the GIA Gem Laboratory in Carlsbad, provided commentary on the inclusion analysis. The colored diamond color grading staff at GIA in New York and Carlsbad helped identify several important discussion points for the article. Numerous members of the diamond trade gave their time and assistance through the loan of yellow diamonds and helpful discussions. Among them, the authors thank Isaac Wolf, Mates Witriol, and Lewis Wolf of Lewis Wolf Trading; Martin Kirschenbaum of M. Kirchenbaum Trading Inc.; Louis Glick of Louis Glick Diamond Corp.; Kevo Ayvazian of KJA Diamonds Int'l Corp.; Bruno Scarselli of the Scarselli family; Nir Livnat of The Steinmetz Group; Mace Blickman of Jerry Blickman Inc.; Nancy Smid of Safdico USA; Jonathon and Alison Doppelt of Jonathon Doppelt Inc.; and Ara Arslanian of Cora Diamond Corp. 


\section{REFERENCES}

Anderson B.W. (1943a) Absorption and luminescence in diamond, Part I. The Gemmologist, Vol. 12, No. 138, pp. 21-22.

Anderson B.W. (1943b) Absorption and luminescence in diamond, Part II. The Gemmologist, Vol. 12, No. 139, pp. 25-27.

Anderson B.W. (1962) Lines and line systems in the fluorescence spectra of diamonds. Journal of Gemmology, Vol. 8, No. 5, pp. 193-202.

Anderson B.W. (1963) The classification of diamonds on the basis of their absorption and emission of light. Journal of Gemmology, Vol. 9, No. 2, pp. 44-54.

Anderson B.W., Payne C.J. (1956) The spectroscope and its applications to gemmology. The Gemmologist, Vol. 25, No. 300, pp. 115-119.

Balfour I. (1997) Famous Diamonds. Christie, Manson and Woods Ltd., London.

Balfour I. (2000) Famous Diamonds, 4th ed. Christie, Manson and Woods Ltd., London.

Bauer M. (1904) Precious Stones, translated by L.J. Spenser. Charles Griffin \& Company Ltd., London.

Briddon P.R., Jones R. (1993) Theory of impurities in diamond. Physica B, Vol. 185, pp. 179-189.

Bursill L.A., Glaisher R.W. (1985) Aggregation and dissolution of small and extended defect structures in Type Ia diamond. American Mineralogist, Vol. 70, pp. 608-618.

Cassedanne J.P. (1989) Diamonds in Brazil. Mineralogical Record, Vol. 20, No. 5, pp. 325-336.

Clark C.D., Ditchburn R.W., Dyer H.B. (1956a) The absorption spectra of natural and irradiated diamonds. Proceedings of the Royal Society, Vol. A234, pp. 363-381.

Clark C.D., Ditchburn R.W., Dyer H.B. (1956b) The absorption spectra of irradiated diamonds after heat treatment. Proceedings of the Royal Society, Vol. A237, pp. 75-89.

Collins A.T. (1978) Investigating artificially colored diamonds. Nature, Vol. 273, No. 5664, pp. 654-655.

Collins A.T. (1980) Vacancy enhanced aggregation of nitrogen in diamond. Journal of Physics C: Solid State Physics, Vol. 13, pp. 2641-2650.

Collins A.T. (1982a) Colour centres in diamond. Journal of Gemmology, Vol. 18, No. 1, pp. 37-75.

Collins A.T. (1982b) A spectroscopic survey of naturally-occurring vacancy-related colour centres in diamond. Journal of Physics D: Applied Physics, Vol. 15, pp. 1431-1438.

Collins A.T. (1984) Pitfalls in color grading diamonds by machine. Gems ef Gemology, Vol. 20, No. 1, pp. 14-21.

Collins A.T. (2001) The colour of diamond and how it may be changed. Journal of Gemmology, Vol. 27, No. 6, pp. 341-359.

Collins A.T., Davies G., Woods G.S. (1986) Spectroscopic studies of the H1b and H1c absorption lines in irradiated, annealed type-Ia diamonds. Journal of Physics C: Solid State Physics, Vol. 19, pp. 3933-3944.

Copeland L.L., Martin J.G.M. (1974) Diamonds: Famous, Notable and Unique, revised by R.A.P. Gaal and J. Taylor. Gemological Institute of America, Santa Monica, CA.

Crowningshield G.R. (1957-8) Spectroscopic recognition of yellow bombarded diamonds and bibliography of diamond treatment. Gems e) Gemology, Vol. 9, No. 4, pp. 99-104, 117

Crowningshield G.R. (1959) Highlights at the Gem Trade Lab in New York. Gems « Gemology, Vol. 9, No. 9, p. 269.

Crowningshield G.R. (1965) Developments and highlights at the Gem Trade Lab in New York: Clouds in natural-color brown diamonds. Gems «) Gemology, Vol. 11, No. 9, pp. 269-270.

Crowningshield G.R. (1994) Gem Trade Lab Notes: Characteristic inclusions in fancy-color diamonds. Gems ef Gemology, Vol. 30, No. 1, pp. 41-42.

Davies G. (1972) The effect of nitrogen impurity on the annealing of radiation damage in diamond. Journal of Physics C: Solid State Physics, Vol. 5, pp. 2534-2542.
Davies G. (1981) The origin of the "N2" absorption band in natural yellow diamonds. Portugaliae Physica, Vol. 13, No. 1-2, pp. 241-261.

Davies G. (1994) Properties and Growth of Diamond. Institution of Electrical Engineers, London.

Davies G., Summersgill I. (1973) Nitrogen dependent optical properties of diamond. Diamond Research 1973, pp. 6-15.

Davies G., Welbourn C.M., Loubser J.H.N. (1978) Optical and electron paramagnetic effects in yellow Type Ia diamonds. Diamond Research 1978, pp. 23-30.

De Weerdt F., Van Royen J. (2001) Defects in coloured natural diamonds. Diamond and Related Materials, Vol. 10, pp. 474-479.

Dyer H.B., Matthews I.G. (1957) The fluorescence of diamond. Proceedings of the Royal Society, Vol. A243, pp. 320-335.

Dyer H.B., Raal F.A., Du Preez L., Loubser J.H.N. (1965) Optical absorption features associated with paramagnetic nitrogen in diamond. Philosophical Magazine, Vol. 11, No. 112, pp. 763-773.

Field J.E. (1992) The Properties of Natural and Synthetic Diamonds. Academic Press, London.

Fisher D., Spits R.A. (2000) Spectroscopic evidence of GE POL HPHT-treated natural type IIa diamonds. Gems «) Gemology, Vol. 36, No. 1, pp. 42-49.

Fritsch E. (1998) The nature of color in diamonds. In G. Harlow, Ed., The Nature of Diamonds, Cambridge University Press, Cambridge, UK.

Fritsch E., Scarratt K. (1992) Natural-color nonconductive gray-toblue diamonds. Gems $\nrightarrow$ Gemology, Vol. 28, No. 1, pp. 35-42.

GIA Diamond Dictionary (1993) Gemological Institute of America, Santa Monica, CA.

Gleason B. (1985) Notable Diamonds of the World. Diamond Promotion Service, New York.

Harris J.W., Hawthorne J.B., Oosterveld M.M. (1979) Regional and local variations in the characteristics of diamonds from southern Africa kimberlites. In F.R. Boyd and H.O.A. Meyer, Eds., Kimberlite, Diatremes and Diamonds: Their Geology, Petrology, and Geochemistry, Vol. 1, Proceedings of the Second International Kimberlite Conference, American Geophysical Union, Washington. D.C., pp. 27-41.

Haske M.D. (2000) Yellow diamonds. The Guide, Vol. 19, Issue 5, Part 1, pp. 8-10.

Hofer S.C. (1998) Collecting and Classifying Coloured Diamonds-An Illustrated History of the Aurora Collection. Ashland Press, New York.

Janse A.J.A. (1995) A history of diamond sources in Africa: Part 1. Gems « Gemology, Vol. 31, No. 4, pp. 228-255.

Kaminsky F.V., Khachatryan G.K. (2001) Characteristics of nitrogen and other impurities in diamond, as revealed by infrared absorption data. The Canadian Mineralogist, Vol. 39, pp. $1733-1745$

Kerr W.C. (1982) A report on the new Watermeyer split-facet diamond cuts. Gems «) Gemology, Vol. 18, No. 3, pp. 154-159.

Kiflawi I., Bruley J., Luyten W., VanTendeloo G. (1998) "Natural" and "man-made" platelets in type Ia diamonds. Philosophical Magazine B, Vol. 78, No. 3, pp. 299-314.

King J.M., Moses T.M., Shigley J.E., Liu Y. (1994) Color grading of colored diamonds at the GIA Gem Trade Laboratory. Gems et) Gemology, Vol. 30, No. 4, pp. 220-242.

King J.M., Moses T.M., Shigley J.E., Welbourn C.M., Lawson S.C., Cooper M. (1998) Characterizing natural-color type IIb blue diamonds. Gems 4 Gemology, Vol. 34, No. 4, pp. 246-268.

King J.M., Shigley J.E., Guhin S.S., Gelb T.H., Hall M. (2002) Characterization and grading of natural-color pink diamonds. Gems «) Gemology, Vol. 38, No. 2, pp. 128-147.

King J.M., Shigley J.E. (2003) An important exhibit of seven rare gem diamonds. Gems ↔ Gemology, Vol. 39, No. 2, pp. 136-143. 
Koivula J.I. (2000) MicroWorld of Diamonds: A Visual Reference. Gemworld International, Northbrook, Illinois, $157 \mathrm{pp}$.

Liddicoat R.T. (1976) Developments and Highlights at GIA's Lab in Santa Monica: A true canary. Gems थ) Gemology, Vol. 15, No. 8, p. 235.

Mani A. (1944) The fluorescence and absorption spectrum of diamond in the visible region. Proceedings of the Indian Academy of Sciences, Vol. A19, pp. 231-252, plates 8-13.

Mawe J. (1813) A Treatise on Diamonds and Precious Stones. Longman, Hurst, Rees, Orme and Brown, London.

Meyer H.O.A. (1987) Inclusions in diamond. In P.H. Nixon, Ed. Mantle Xenoliths, New York, John Wiley and Sons, pp. 501-523.

Mita Y. (1996) Change of absorption spectra in type Ib diamond with heavy neutron irradiation. Physical Review B, Vol. 53, No. 17, pp. 11360-11364.

National Bureau of Standards (1976) Color: Universal Language and Dictionary of Names. NBS Special Publication 440, S.D. Catalog No. C13.10:440, U.S. Government Printing Office, Washington D.C.

Nayar P.G.N. (1941) The luminescence, absorption and scattering of light in diamonds: Part III. Absorption. Proceedings of the Indian Academy of Sciences, Vol. A14, pp. 1-17, plates 1-3.

Overton T.W. (2002) Legal protection for proprietary diamond cuts. Gems ↔ Gemology, Vol. 38, No. 4, pp. 310-325.

Robertson R., Fox J.J., Martin A.E. (1934) Two types of diamond. Philosophical Transactions of the Royal Society of London, Vol. A232, pp. 463-535.

Sato K., Sunagawa I. (1982) Quantitative evaluation of colour of diamonds by spectrophotometric method. Journal of the Gemmological Society of Japan, Vol. 9, No. 4, pp. 3-17 [in English; pp. 87-101 in Japanese].

Scarratt K. (1979) Investigating the visible spectra of coloured diamonds. Journal of Gemmology, Vol. 16, No. 7, pp. 433-447.

Scarratt K. (1982) The identification of artificial coloration in diamond. Gems «) Gemology, Vol. 18, No. 2, pp. 72-78.

Tavernier J-B. (1676) Travels in India. Translated by V. Ball, W. Crooke, Ed., republished in 1977 by Oriental Books Reprint Corp., New Delhi, India.

Vendrell-Saz M., Nogués-Carulla J.M., Mones-Roberdeau L., Bosch-Figueroa J.M. (1980) Transmission et absorption des diamantes taillés de la série "cape." Revue de Gemmologie a.f.g., Vol. 64, pp. 20-24.

Wade F.B. (1920) A few words on fancy colored diamonds. The Jeweler's Circular, Vol. 80, No. 1, pp. 187-189.

Wang W., Mayerson W. (2002) Symmetrical clouds in diamond: The hydrogen connection. Journal of Gemmology, Vol. 28, No. 3, pp. 143-152.

Wilks J., Wilks E. (1994) Properties and Applications of Diamond. Butterworth Heinemann Ltd., Oxford, UK.

Woods G.S. (1984) Infrared absorption studies of the annealing of irradiated diamonds. Philosophical Magazine B, Vol. 50, pp. 673-688.

Woods G.S., Collins A.T. (1982) The $1450 \mathrm{~cm}^{-1}$ infrared absorption in annealed, electron-irradiated type Ia diamonds. Journal of Physics C: Solid State Physics, Vol. 15, pp. L949-L952.

Woods G.S., Collins A.T. (1986) New developments in spectroscopic methods for detecting artificially coloured diamonds. Journal of Gemmology, Vol. 20, No. 2, pp. 75-82.

Zaitsev A.M. (2001) Optical Properties of Diamond: A Data Handbook. Springer Verlag, Berlin.

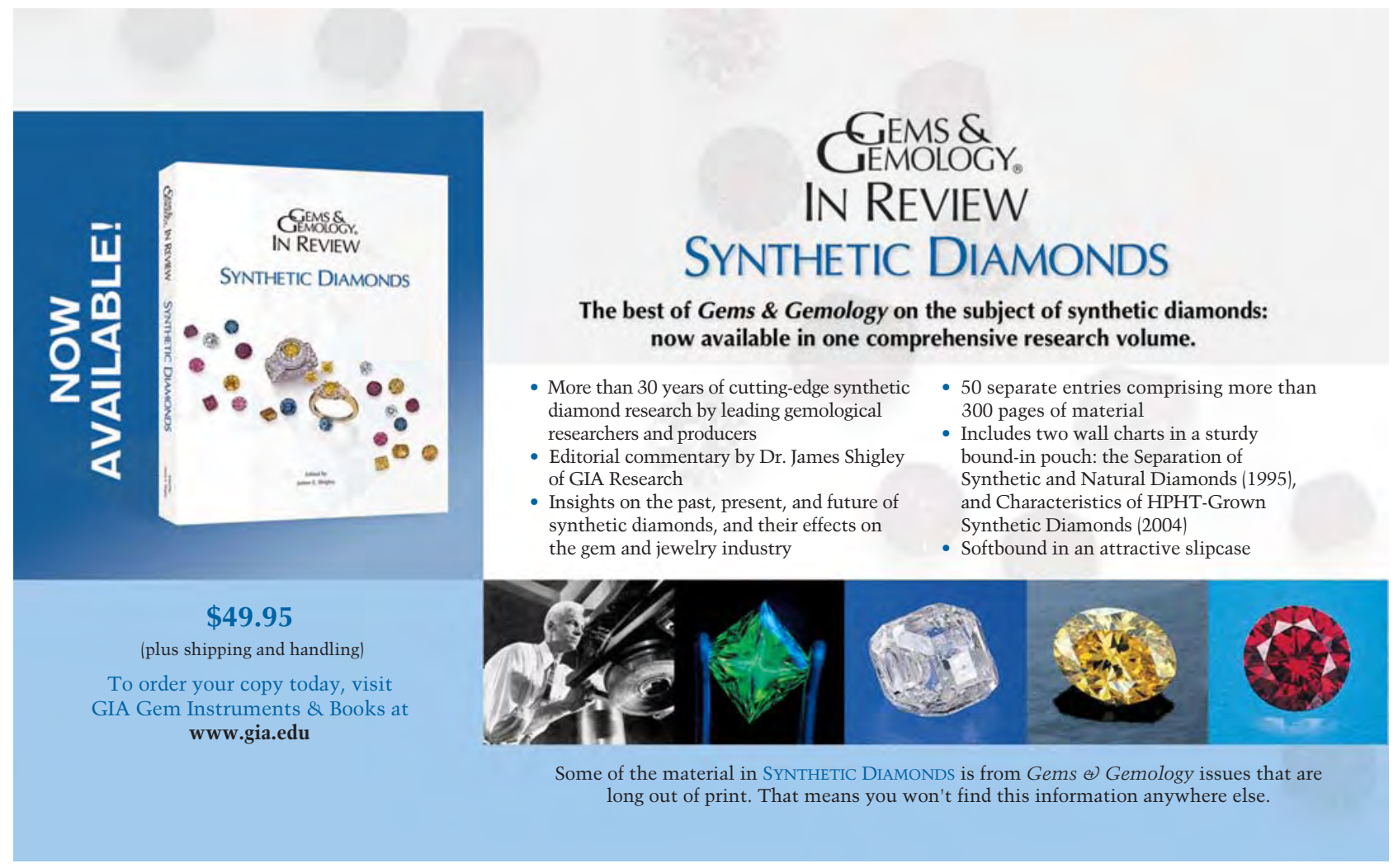

